\title{
ETNOBOTÁNICA HISTÓRICA DE GRUPOS CRIOLLOS DE ARGENTINA III: IDENTIFICACIÓN TAXONÓMICA Y ANÁLISIS DE DATOS NO-MEDICINALES DEL CHACO HÚMEDO PROVENIENTES DE LA ENCUESTA NACIONAL DE FOLKLORE DE 1921
}

\author{
GUSTAVO F. SCARPA ${ }^{1} \&$ CINTIA N. ROSSO ${ }^{2}$
}

\begin{abstract}
Summary: Scarpa, G. F. \& C. N. Rosso. 2018. Historical ethnobotany of Criollos groups from Argentina III. Taxonomic identification and analysis of non-medicinal data from Eastern Chaco found in the 1921 National Survey of Folklore. Bonplandia 27(1): 31-57.
\end{abstract}

The aim of this study is to identify, update and analyze ethnobotanical data from Criollos groups of Eastern Chaco found in the 1921 National Survey of Folklore. Since plants were named by their vernacular names, the scientific nomenclature is estimated on the basis of an exhaustive bibliographic research. A total of 1242 ethnobotanical data were registered and assigned to 308 botanical taxa referred through 294 vernacular names. For the last ones, a plausible taxonomic identification could be found in 1565 bibliographic reports. Results show that $2 / 3$ of these data (814) correspond to medicinal plant uses, while the remaining (428) became the objective of this study. Most of them (120 data, 78 taxa) refers to religious meanings of plants, construction uses (55, 47 taxa), cultigens (52, 52 taxa), and food (47 data, 38 taxa). Other use-categories show minor proportions. This article discusses many issues about this data characterization and concludes that it constitutes the major contribution to the ethnobotany of the Criollos of the Eastern Chaco up to the present, for both its quantity as their quality.

Key words: Criollos, Historical ethnobotany, Humid Chaco, NE Argentina.

Resumen: Scarpa, G. F. \& C. N. Rosso. 2018. Etnobotánica histórica de grupos criollos de Argentina III: Identificación taxonómica y análisis de datos no-medicinales del Chaco Húmedo provenientes de la Encuesta Nacional de Folklore de 1921. Bonplandia 27(1): 31-57.

Se procura identificar, actualizar y analizar la información sobre usos y significaciones vegetales de los criollos del Chaco Húmedo en la Encuesta Nacional de Folklore de 1921. Debido a que las plantas aparecen referidas por su nombre vulgar, se estiman sus correspondencias con la nomenclatura científica sobre la base de una exhaustiva búsqueda bibliográfica. Se registran 1242 datos etnobotánicos asignados a 308 taxa botánicos referidos a través de 294 nombres vulgares, para los cuales se halla una identificación taxonómica plausible a partir de 1565 consultas bibliográficas totales analizadas. Los resultados indican que $2 / 3$ de tales datos (814) corresponden a usos medicinales de las plantas, mientras que el resto (428 datos) es objeto de este trabajo. La mayoría alude a significaciones de las plantas en la religiosidad (120, 78 taxa), en construcciones (55, 47 taxa), como cultígenos $(52,52$ taxa) y como alimentos (47, 38 taxa), mientras que otras categorías de uso registran participaciones mucho menores. Se

${ }^{1}$ Investigador Independiente del CONICET, Museo Argentino de Ciencias Naturales "Bernardino Rivadavia"CONICET. Ángel Gallardo 470, $2^{\circ}$ piso (C1405DJR) C.A.B.A. E-mail: gscarpa@macn.gov.ar

${ }^{2}$ Investigadora Asistente del CONICET, Museo Argentino de Ciencias Naturales "Bernardino Rivadavia"-CONICET. Ángel Gallardo 470, $2^{\circ}$ piso (C1405DJR) C.A.B.A. E-mail: cintia_rosso@macn.gov.ar 
discuten variados aspectos en torno a las características de estos datos y se concluye que, hasta la actualidad, estos constituyen el mayor aporte a la etnobotánica de los criollos del Chaco Húmedo tanto por su cantidad como por su calidad.

Palabras clave: Criollos, Chaco Húmedo, NE Argentina, Etnobotánica histórica.

\section{Introducción}

Este trabajo se inscribe en un proyecto más amplio consistente en estudiar la etnobotánica histórica de grupos criollos de Argentina a partir de diferentes tipos de fuentes primarias. Las primeras dos contribuciones al respecto consisten en el análisis, puesta en valor y adscripción biocultural de los datos sobre etnobotánica criolla identificados en el catálogo de la Exposición Universal de París de 1889, realizada por los autores (Scarpa et al., 2016; Scarpa, 2017).

La Encuesta Nacional de Folklore del año 1921 fue el primer proyecto sistemático y abarcativo de recopilación folklórica ejecutado en la Argentina (Arovich de Bogado, 2005). La misma incluye una gran riqueza de datos de diversa índole, entre los que destacan aquellos de interés económico, histórico, cultural y etnobotánico en general. $\mathrm{Su}$ objetivo primario fue relevar y documentar distintas manifestaciones folklóricas de diversas regiones de Argentina, tanto de la producción oral regional (leyendas, cancioneros, etc.), como prácticas culturales diversas y aspectos de la religiosidad popular asociados a plantas y animales, entre otras. El Consejo Nacional de Educación encargó a docentes de ciertas escuelas rurales del nivel primario de todo el territorio nacional, la tarea de oficiar de intermediarios con la comunidad para la recolección y el registro de dichas manifestaciones orales a partir de la realización de una encuesta. Para ello se envió previamente un instructivo que incluía un esquema pautado acerca de cómo llevar a cabo tal recolección de datos. Los resultados de la misma quedaron plasmados en 87869 folios que aún permanecen inéditos. Estos últimos han redundado en investigaciones de tipo historiográfico tales como las realizadas por Farberman (2005) -quien confronta el corpus documental sobre hechicería del siglo XVIII en el Tucumán colonial con los datos sobre este tema en la ENF de 1921-, Arovich de Bogado (2005) -quien analiza desde dicha perspectiva los textos recogidos en la actual provincia del Chaco- y por Dahhur (2016) -centrado en la tensión suscitada entre los "saberes" de los docentes y de los curanderos en la provincia de Buenos Aires-. A pesar de ello, no existe al momento ninguna publicación que rescate y ponga en valor los datos etnobotánicos que se desprenden de sus resultados para ninguna región de la Argentina, por lo cual el presente trabajo constituye la primera contribución en este sentido.

Entre los datos de interés etnobotánico registrados se encuentran variados tipos de usos y significaciones de las plantas, entre los que se destacan los de índole medicinal, forrajero, ritual, asociados con la religiosidad popular, para construcción -entre otros-, siendo los del primer tipo aquellos que más destacan por su cantidad y calidad. Sin embargo, resulta un escollo de importancia para la recuperación de estos datos el hecho de que todas las entidades vegetales se hallen referidas por su nombre vernáculo. A lo largo de este trabajo los autores nos proponemos superar este inconveniente -en la medida de lo posible-, a partir de la aplicación de una metodología que procura estimar sus identidades respectivas a partir de la consulta de numerosos estudios botánicos y etnobotánicos que refieran las correspondencias entre la nomenclatura científica y la vernácula del área biocultural que aquí tratamos: la de los Criollos del Chaco Húmedo. El valor de esta encuesta a los fines de recuperar datos etnobotánicos históricos de dicha área biocultural resulta de suma importancia por varias razones. En primer lugar, los antecedentes que existen para la etnobotánica de este grupo humano son escasos, ya que los únicos trabajos que presentan algunos datos al respecto son los de Schulz (1976; 1997†), Martínez Crovetto (1981a; 1981b), Pirondo (2016), Scarpa et al. (2016) y Scarpa (2017), la mayoría de 
los cuales enfatizan en sus obras aspectos fitonímicos y usos medicinales de las plantas. Por otra parte, su valor histórico resulta destacable de por sí -tanto para el patrimonio cultural argentino como para la etnobotánica de esta área biocultural- ya que, por haber sido documentados hace ya 95 años, no existe la posibilidad de su actual recopilación a campo. Esta imposibilidad radica en las profundas transformaciones ambientales y socioculturales acaecidas como consecuencia de los altos niveles de deforestación de extensas áreas destinadas a la explotación agrícola-ganaderaforestal intensiva y a las operadas dentro de la sociedad criolla del Chaco Húmedo desde 1921 hasta la actualidad, respectivamente (Guinzburg \& Adámoli, 2006; Maeder, 2007).

El objetivo general de este trabajo consiste en identificar, actualizar y analizar el conjunto de información sobre usos y significaciones de las plantas de los criollos del Chaco Húmedo incluidos en la Encuesta Nacional de Folklore (ENF) de 1921. Dada la gran cantidad de datos allí referidos, los objetivos particulares de esta primera contribución consisten en: a) describir el contexto socio-histórico y cultural de la fuente primaria de procedencia de los datos, b) explicitar la metodología empleada para la estimación de las identidades botánicas a las que refieren los nombres vulgares, y c) detallar y analizar las numerosas aplicaciones no-medicinales que se han podido distinguir a lo largo de dicha encuesta.

\section{Materiales y Métodos}

La ENF de 1921 consta de un total de 3224 legajos manuscritos -enviados por 3250 docentes- que actualmente se hallan depositados en el Instituto Nacional de Antropología y Pensamiento Latinoamericano (INAPL) -dependiente de la Secretaría de Cultura de la Nación-, en la Ciudad Autónoma de Buenos Aires (Fernández Latour de Botas, 2002). El material está separado por provincias y se halla preservado en la forma de rollos de microfilms. El criterio de selección de la información utilizado fue que esta hubiera sido recabada en localidades de la ecorregión del Chaco Húmedo argentino, cuyos límites geográficos coinciden con los definidos por Burkart et al. (1999) y por The Nature Conservancy et al. (2005). Según este criterio se consultaron los microfilms correspondientes a las provincias de Chaco (rollos $n^{\circ} 29,30,31$ y 32), Corrientes $\left(n^{\circ} 28\right)$, Formosa $\left(n^{\circ} 41\right)$ y Santa Fe $\left(n^{\circ} 78\right.$, $79,80,81,82$ y 83), los cuales incluyeron un total de 134 legajos correspondientes a cada uno de los docentes de escuelas rurales que participaron en la ENF. Las escasas encuestas registradas en cinco localidades de la provincia de Formosa no pertenecerían a poblaciones criollas del Chaco Húmedo, razón por la cual no fueron incluidas en este trabajo. En el mapa de la Fig. 1 se presenta la ubicación geográfica de 59 de las 60 localidades de procedencia de los datos (la excepción corresponde al Paraje Talatí o "Talaty" -Corrientes, 2752'59"S y $57^{\circ} 43^{\prime} 59^{\prime \prime} \mathrm{W}$ - por ubicarse fuera del área mapeada).

Cada uno de los legajos referidos consiste en informes de los docentes redactados de forma manuscrita $y$, excepcionalmente, mecanografiado. Cada uno de ellos consta de una carátula en la que figura la siguiente información: $\mathrm{n}^{0}$ de legajo, $\mathrm{n}^{0}$ de escuela, localidad y nombre del/la docente que lo redactó. $\mathrm{Su}$ extensión varía desde una página hasta varias decenas, incluso separadas entre sí en la forma de varios "envíos" numerados correlativamente. En ocasiones, algunas páginas hacen alusión a distintos "informantes" -no docentes- que habrían referido los datos con su nombre completo y edad respectiva, aunque en otros la información suministrada provenía del propio maestro o bien era extraída de bibliografía. En este último caso, los datos etnobotánicos que de allí habrían podido desprenderse fueron descartados por no corresponder al acervo popular que aquí se pretende relevar.

La perspectiva etnobotánica aquí empleada es aquella que se ocupa de estudiar los significados de las plantas científicamente identificadas dentro del contexto sociocultural donde estos cobran sentido (Arenas, 1987; Scarpa, 2012a). La metodología específica empleada es la correspondiente a la etnobotánica histórica, la cual considera a los datos del pasado como una fuente de información primaria, sobre los cuales se aplica el método clásico etnobotánico 


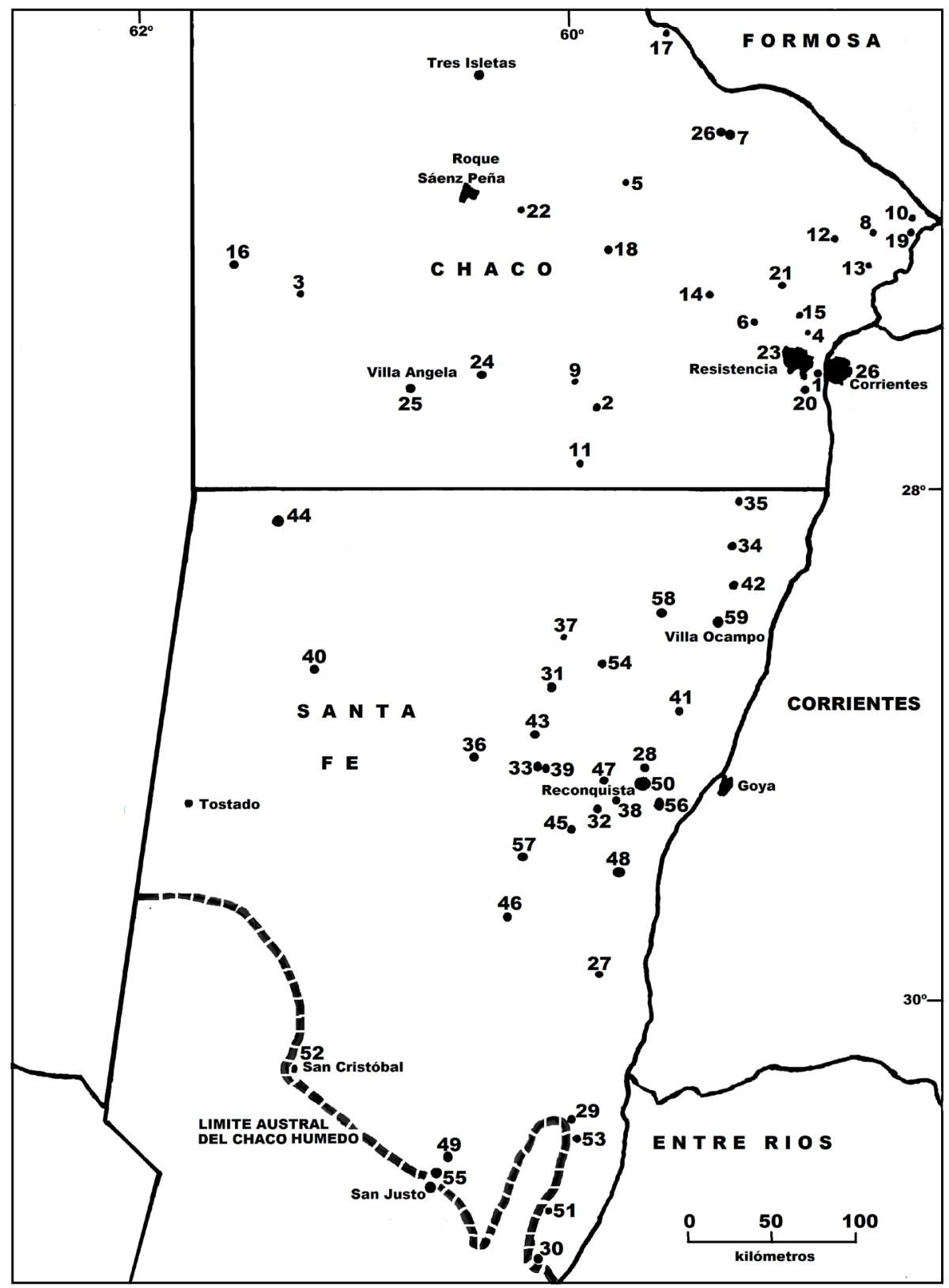

Fig. 1. Localización de las escuelas que participaron en la ENF de 1921.

Fig. 1. Location of schools involved in the ENF of 1921.

Referencias: 1) Barranqueras, 2) Charadai, 3) Charata, 4) Colonia Benítez, 5) Colonia Palmar, 6) Colonia Popular, 7) Lib. Gral. San Martín, 8) General Vedia, 9) Horquilla, 10) La Posta, 11) La Sabana, 12) Lapacho, 13) Las Palmas, 14) Makallé, 15) Margarita Belén, 16) Palmar Norte, 17) Presidencia Roca, 18) Presidente de la Plaza, 19) Puerto Bermejo, 20) Puerto Vilela, 21) Punta de Riel, 22) Quitilipi, 23) Resistencia, 24) Samuhu, 25) Villa Ángela, 26) Corrientes, 27) Alejandra, 28) Avellaneda, 29) California, 30) Cnia. Campo del Medio, 31) Colmena, 32) Colonia Ella, 33) Desvío km 285, 34) El Rabón, 35) Florencia, 36) Fortín Olmos, 37) Golondrina, 38) La Lola, 39) La Zulema, 40) Las Chuñas, 41) Las Garzas, 42) Las Toscas, 43) Garabato, 44) Los Saladillos, 45) Malabrigo, 46) Margarita, 47) Nicanor Molina, 48) Romang, 49) Ramayón, 50) Reconquista, 51) Saladero Cabral, 52) San Cristóbal, 53) San Javier, 54) Tartagal, 55) Cnia. Tres Reyes, 56) Cnia. Urdaniz, 57) Vera, 58) Villa Ana y 59) Villa Ocampo. 
(Medeiros, 2009; Rosso, 2012; Rosso \& Scarpa, 2012).

En suma, la metodología aplicada incluyó las siguientes fases de análisis: $1^{\circ}$ ) contextualización espacio-temporal, sociohistórica y cultural de los datos a los fines de brindar un marco interpretativo para su análisis; $2^{\circ}$ ) identificación botánica de los taxa a los que hacen referencia los nombres vulgares de las plantas -en cuanto fuera posiblea partir de correspondencias citadas en la bibliografía entre estos últimos y los nombres científicos; $3^{\circ}$ ) análisis general de los datos etnobotánicos, clasificados por categoría de uso (medicinal, forrajero, construcción, etc.); y $4^{\mathrm{o}}$ ) análisis detallado de los datos etnobotánicos no-medicinales recabados, de acuerdo a las aplicaciones específicas registradas para cada una de tales categorías.

En términos generales se aplicó la metodología ya empleada en otros trabajos de etnobotánica histórica, entre los cuales pueden citarse los de Rosso \& Scarpa (2012) y Campos Navarro \& Scarpa (2013). Esta consistió en efectuar una búsqueda bibliográfica de las identidades botánicas asociadas a cada uno de los nombres vulgares referidos en la ENF para los criollos del Chaco argentino sensu lato (Scarpa, 2012b), para los criollos del Chaco Húmedo e Iberá (p. ej. Schulz, 1976; 1997†; Martínez Crovetto, 1981a; Pirondo, 2016) sensu stricto, así como para Argentina en sentido amplio (p. ej. Dimitri, 1987; De la Peña \& Pensiero, 2004). Las identificaciones botánicas totales halladas para los nombres vulgares (n.v.) mencionados en la ENF fueron ordenadas y sistematizadas en una base de datos que responde al programa MS-Access. En segunda instancia, estas se clasificaron según definieran entre sí una relación de tipo "unívoca" (un taxón botánico para un n.v.); "biunívoca" (dos especies para un n.v.) o "genérica" (varias especies de uno o más géneros botánicos para un n.v.). Las correspondencias incluidas en las primeras dos categorías fueron directamente validadas a los fines de este trabajo, mientras que las genéricas fueron analizadas según los criterios indicados a continuación. En primer lugar, se descartaron aquellas correspondencias genéricas que involucraran taxa que no vegetan en la región biogeográfica Chaqueña, según la distribución referida para cada uno de ellos en la base de datos actualizada de la Flora Argentina (2017). Por otro lado, se consideraron como "prototípicas" del complejo biocultural ${ }^{3}$ aquí considerado a aquellas correspondencias que contaran con mayoría de citas para el área del Chaco Húmedo argentino, es decir, las mencionadas por Wernicke (1944), Schulz (1976; 1997†), Martínez Crovetto (1981a), Scarpa (2012b), Pensiero et al. (2005), Pirondo (2016) y Rosso \& Scarpa (2012). Por último, aquellas correspondencias genéricas sobre las que no pudo establecerse este tipo de asociación fueron descartadas.

\section{Resultados}

\section{1) Contexto socio-histórico y cultural de los datos}

La ENF de 1921 se enmarca dentro de un proyecto tendiente a reforzar la identidad nacional a pedido del gobierno argentino. En efecto, uno de los objetivos explícitos de la ENF consistió en preservar los saberes nacionales antes que estos fueran "mezclados" con aquellos propios de los inmigrantes, cuya masiva participación en la sociedad nacional se había incrementado enormemente en las décadas anteriores a 1920 (por ello se recomendaba que la recolección no debía contener ningún elemento "exótico al suelo"-sic-). Los encargados de llevarla a cabo fueron docentes de escuelas rurales primarias de la ley Láinez, quienes debían recopilar "leyendas", "costumbres", "canciones" y "creencias" junto con otras manifestaciones folklóricas del territorio argentino. La Ley 4874, conocida como Ley Láinez, fue dictada en 1884 con el propósito de extender la educación pública, laica y gratuita a todo el territorio nacional a través de la creación de escuelas primarias y rurales en aquellas provincias que lo pidieran.

Luego de las últimas campañas militares realizadas a fines del siglo XIX contra los indígenas asentados en las actuales provincias

\footnotetext{
${ }^{3}$ Un "complejo bio-cultural" según Toledo \& BarreraBassols (2008) alude a la interacción de cada cultura con su propio ecosistema local y con la combinación de paisajes y sus respectivas biodiversidades contenidos en ellos.
} 
de Chaco y Santa Fe, se inicia la instalación de las primeras colonias agrícolas a cargo de inmigrantes europeos (Maeder, 2007). Esta situación sufrió cambios entre 1900 y 1915 a consecuencia de la radicación de la industria del tanino, la expansión hacia las tierras al oeste y el crecimiento general alcanzado en la región. Estas actividades, así como la ampliación de las ya existentes, se superpusieron a los obrajes y aserraderos que funcionaban antiguamente, lo cual absorbió numerosa mano de obra procedente de las provincias de Corrientes y Santiago del Estero (Maeder, 2007). Para la misma época, en el sudoeste chaqueño comenzó a desplegarse la producción agrícola -especialmente la del algodón- y la explotación ganadera. Junto con los antiguos pobladores, las tropas acantonadas en el lugar y los indígenas de los alrededores formaron el primer núcleo estable del Chaco conformando una población de característica multiétnica (Ministerio De Planificación Federal, Inversión Pública y Servicios, 2006). A principios del siglo XX el Chaco Húmedo santafecino experimentó un alto crecimiento demográfico debido, principalmente, a migrantes de origen correntino y entrerriano que se ubicaron en el norte de la provincia y aledaños a las zonas ribereñas (Quiñonez, 2000). A diferencia de lo ocurrido al oeste del río Paraná, el territorio de Corrientes -cuya población de antiguo origen guaraní se había mestizado partir de la expansión ganadera criolla desde el siglo XVIII- se convirtió en un territorio de emigración debido a continuos períodos de turbulencia política, a su aislamiento y a la imposibilidad de acceder a la propiedad de la tierra (Quiñonez, 2000). Como corolario de esta dinámica histórica, la conformación cultural del Chaco Húmedo fue la resultante de un mestizaje entre una mayoría criolla de antigua raigambre guaranítica (principalmente proveniente de la provincia de Corrientes) con una minoría de santiagueños, indígenas de origen chaquense e inmigrantes europeos procedentes de distintas oleadas migratorias. Este acervo se halla implícitamente señalado en la ENF en la forma de numerosas referencias a producciones orales en idioma guaraní (versos, adivinanzas, canciones, himnos, etc.) que provienen de la provincia de Corrientes. Uno de los encuestados afirma de manera explícita que "El Chaco santafecino y el Chaco propiamente dicho participan de las mismas costumbres y supersticiones de la provincia de Corrientes, de donde han sido introducidas por los emigrados de esa provincia" (Mauro Romero, Colmena, Provincia de Santa Fe, Legajo no 205).

\section{2) Identificaciones botánicas a partir de nombres vulgares}

Se puede reconocer un total de 337 nombres vulgares de plantas -castellano o guaraní- con algún uso o significado en la ENF de 1921. Dicha cuantificación incluye la homologación de nombres vulgares que involucran calificativos con idéntico significado (como por ejemplo: "del campo" / "silvestre" / "cimarrón" y "cadillo chico" / "cadillito", etc.), así como algunas variantes fonéticas de ciertos fitónimos. Entre estos últimos se incluyen los derivados de la refonologización castellana de fitónimos procedentes del idioma guaraní. Uno de los casos más frecuentes es aquél derivado originalmente del genérico correspondiente a la forma de vida "árbol" (o "palo") -en guaraní "ivyrã"-, el cual es indistintamente refonologizado con el morfema "ivirá" ("ivirápitá") o con los prefijos "iguá-" ("iguajay"), "gua-" ("guayaibí") y "uba-" ("ubajay"), entre otros.

Como resultado de la aplicación de la metodología propuesta pudimos hallar en la bibliografía un total de 782 correspondencias botánicas entre dichos n.v. (337) y un taxa determinado (género y/o especie), a lo largo de 1565 citas bibliográficas recabadas. Para el $40 \%$ de dichos n.v. (135) se pudo establecer una relación unívoca entre cada uno de ellos y una especie botánica, para 21 n.v. (6\%) una de tipo biunívoca (dos especies por n.v.), para 10 n.v. (3\%) no se obtuvo ninguna identificación botánica (por lo que fueron descartadas), mientras que para el resto (171 n.v., $51 \%$ ) se obtuvieron correspondencias de tipo genéricas (cada n.v. correspondía a más de un género botánico o bien a 3 o más especies de un mismo género). A su vez, el análisis de las asociaciones de tipo genérico mostró que 33 de ellas (10\%) no eran propias de esta región (por lo que fueron descartadas del análisis), 
mientras que su mayoría $(138,41 \%$ del total) sí eran prototípicas del Chaco Húmedo. Dentro de estas últimas, 122 n.v. presentaron correspondencias botánicas con una o dos especies de un mismo género (denominadas "genérica-prototípica"), mientras que 16 n.v. (5\%) lo hacían con más de dos especies de un mismo género (denominada "genéricabotánica”, ya que la identificación alcanzada es a nivel de género botánico).

Como corolario de este análisis se obtuvieron 308 identificaciones botánicas plausibles para un total de 294 n.v. (87\% de los referidos en la ENF) a partir de 1137 citas bibliográficas totales, mientras que sobre 43 n.v. (13\%) o bien no se obtuvo correspondencia alguna o bien estas eran del tipo genéricas no prototípicas para el Chaco Húmedo, razón por la cual fueron descartadas. En la Fig. 2 se grafican los resultados para cada una de las clases de correspondencias halladas.

En la Tabla 1 se detalla la nomenclatura científica de los n.v. de las plantas sobre las que se refirieron usos de carácter no-medicinal, el tipo de correspondencia hallada para cada n.v., las citas bibliográficas que documentan cada una de ellas y una descripción suscinta de los usos no-medicinales registrados en la ENF para cada entidad vegetal identificada.

En la Tabla 2 se resumen las cuantificaciones de los nombres vulgares, taxa botánicos y citas bibliográficas resultantes a lo largo del proceso de estimación de las identidades botánicas a partir de sus correspondencias con los fitónimos referidos en la ENF.

\section{3) Análisis de los datos etnobotánicos}

Se registran 1242 datos etnobotánicos sobre en un total de 2363 reportes individuales de los docentes en la ENF de 1921, de los cuales resulta significativa la importancia asignada a los usos medicinales de las plantas, ya que agrupa un total de 814 datos correspondientes al $65,5 \%$ del total recopilado. El 62,8 \% del total (783) fue consensuado por dos o más fuentes (ya sean colaboradores o referencias bibliográficas para criollos del Chaco argentino), mientras que el resto $(37,7 \% ; 470)$

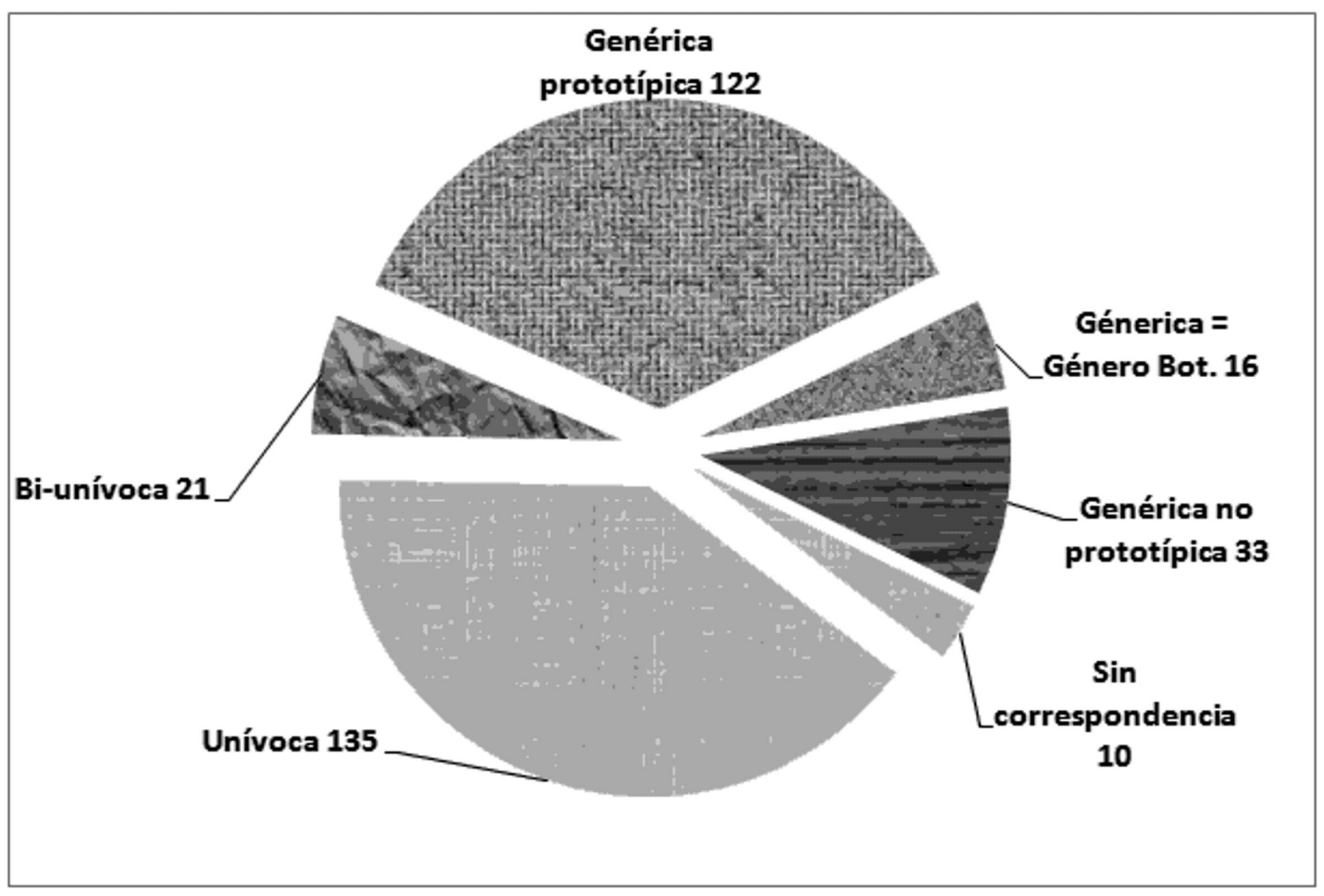

Fig. 2. Tipos de correspondencias entre nombres vulgares y científicos.

Fig. 2. Types of correspondences between common and scientific names. 
Tabla 1. Correspondencias botánicas, usos y significaciones de las plantas referidas con su nombre vulgar en la Encuesta Nacional de Folklore de 1921.

Table 1. Botanical correspondences, uses and plant meanings referred by their common names in the National Survey of Folklore of 1921.

\begin{tabular}{|c|c|c|c|c|}
\hline $\begin{array}{l}\text { Familia Botánica y nombre } \\
\text { científico }\end{array}$ & $\begin{array}{l}\text { Nombre } \\
\text { vulgar }\end{array}$ & Usos / Significaciones & Bibliografía & Categoría \\
\hline \multicolumn{5}{|c|}{ PTERIDOPHYTA } \\
\hline \multicolumn{5}{|l|}{ ANEMIACEAE } \\
\hline $\begin{array}{l}\text { Anemia tomentosa (Savigny) } \\
\text { Sw. }\end{array}$ & Doradilla & $\begin{array}{l}\text { Ritual para obtener su "flor de } \\
\text { curundú" (ver texto) que atrae la } \\
\text { buena suerte }\end{array}$ & $\begin{array}{l}(1),(24),(9), \\
(16),(20), \\
(22),(23)\end{array}$ & GEN-PRO \\
\hline \multicolumn{5}{|l|}{ MARSILEACEAE } \\
\hline $\begin{array}{l}\text { Marsilea ancylopoda A. } \\
\text { Braun }\end{array}$ & $\begin{array}{l}\text { Trébol cuatro } \\
\text { hojas }\end{array}$ & Atrae buenos augurios & (3) & GEN-PRO \\
\hline \multicolumn{5}{|l|}{ PTERIDACEAE } \\
\hline $\begin{array}{l}\text { Adiantum raddianum } \mathrm{C} . \\
\text { Presl, } \\
\text { Adiantum lorentzii Hieron. }\end{array}$ & $\begin{array}{l}\text { Culantrillo o } \\
\text { culandrillo }\end{array}$ & Cultivado. Posee entidad espiritual & $\begin{array}{l}(1),(9),(10) \\
(16),(22)\end{array}$ & GEN-PRO \\
\hline $\begin{array}{l}\text { Hemionitis tomentosa } \\
\text { (Lam.) Raddi }\end{array}$ & Doradilla & $\begin{array}{l}\text { Ritual para obtener su "flor de } \\
\text { curundú" (ver texto) que atrae la } \\
\text { buena suerte }\end{array}$ & & \\
\hline \multicolumn{5}{|c|}{ SPERMATOPHYTA } \\
\hline \multicolumn{5}{|l|}{ ACHATOCARPACEAE } \\
\hline $\begin{array}{l}\text { Achatocarpus praecox } \\
\text { Griseb. }\end{array}$ & Palo tinta & $\begin{array}{l}\text { De sus hojas extraen una tintura } \\
\text { morada }\end{array}$ & (3), (20) & UNI \\
\hline \multicolumn{5}{|l|}{ ADOXACEAE } \\
\hline $\begin{array}{l}\text { Sambucus australis Cham. } \\
\text { \& Schltdl.* }\end{array}$ & Sauco & $\begin{array}{l}\text { Cultivado como ornamental. Posee } \\
\text { entidad espiritual. Se evitaba } \\
\text { dormir debajo por sus "malos } \\
\text { influjos" }\end{array}$ & $\begin{array}{l}(9),(10),(22) \\
(23)\end{array}$ & GEN-PRO \\
\hline \multicolumn{5}{|l|}{ AMARANTHACEAE } \\
\hline $\begin{array}{l}\text { Alternanthera pungens } \\
\text { Kunth }\end{array}$ & $\begin{array}{l}\text { Yerba del } \\
\text { pollo }\end{array}$ & $\begin{array}{l}\text { Sus vástagos sirven de forraje para } \\
\text { el ganado }\end{array}$ & $\begin{array}{l}(3),(9),(10) \\
(17),(22) \\
\quad(23)\end{array}$ & GEN-PRO \\
\hline Amaranthus hybridus & $\begin{array}{l}\text { Yuyo } \\
\text { colorado }\end{array}$ & $\begin{array}{l}\text { Sus vástagos sirven de forraje para } \\
\text { porcinos }\end{array}$ & $(9),(10),(20)$ & UNI \\
\hline $\begin{array}{l}\text { Amaranthus hybridus } \mathrm{L} . \\
\text { Amaranthus viridis } \mathrm{L} .\end{array}$ & $\begin{array}{l}\text { Caarurú o } \\
\text { Amaranto }\end{array}$ & $\begin{array}{l}\text { Ambas plantas auguran a solteras } \\
\text { no conseguir pareja }\end{array}$ & (5), (9), (23) & BI-UNI \\
\hline $\begin{array}{l}\text { Amaranthus viridis } \mathrm{L} . \\
\text { Amaranthus retroflexus } \mathrm{L} \text {. } \\
\text { Amaranthus hybridus } \mathrm{L} \text {. }\end{array}$ & Bledo & $\begin{array}{l}\text { Las cenizas producto de sus } \\
\text { vástagos se emplean como lejía } \\
\text { para elaborar jabón criollo }\end{array}$ & (3) & GEN-BOT \\
\hline \multicolumn{5}{|l|}{ AMARYLLIDACEAE } \\
\hline Allium cepa $\mathrm{L} . *$ & Cebolla & Cultivado & (9), (20) & UNI \\
\hline Allium sativumL.* & Ajo & $\begin{array}{l}\text { Cultivado. Con sus bulbos } \\
\text { ahuyentan víboras, predicen } \\
\text { el futuro y se previenen contra } \\
\text { desgracias }\end{array}$ & $\begin{array}{l}(1),(3),(9) \\
\quad(23)\end{array}$ & UNI \\
\hline Allium ampeloprasum L.* & Ajo guaraní & Bulbo para ahuyentar víboras & $(9)$ & UNI \\
\hline
\end{tabular}




\begin{tabular}{|c|c|c|c|c|}
\hline $\begin{array}{l}\text { Familia Botánica y nombre } \\
\text { científico }\end{array}$ & $\begin{array}{l}\text { Nombre } \\
\text { vulgar }\end{array}$ & Usos / Significaciones & Bibliografía & Categoría \\
\hline \multicolumn{5}{|l|}{ ANACARDIACEAE } \\
\hline Astronium balansae Engl. & Urunday & Madera para construcciones & $\begin{array}{l}\text { (3), (9), (22), } \\
(23)\end{array}$ & UNI \\
\hline Schinopsis balansae Engl. & $\begin{array}{l}\text { Quebracho } \\
\text { colorado }\end{array}$ & $\begin{array}{l}\text { Su madera se usa para } \\
\text { construcciones y su resina como } \\
\text { curtiente y para teñir de morado. } \\
\text { Posee entidad espiritual que castiga } \\
\text { a los hacheros que los cortan en } \\
\text { exceso. Erupción cutánea a quienes } \\
\text { no lo "saludan" }\end{array}$ & $\begin{array}{l}(3),(9),(18) \\
(23)\end{array}$ & UNI \\
\hline Schinus spp. & Molle & $\begin{array}{l}\text { Sus frutos se consumen frescos. } \\
\text { Planta oleaginosa. Su madera se } \\
\text { usa como leña }\end{array}$ & $\begin{array}{c}(24),(3),(9) \\
(10),(20) \\
(23)\end{array}$ & GEN-BOT \\
\hline \multicolumn{5}{|l|}{ ANNONACEAE } \\
\hline $\begin{array}{l}\text { Annona emarginata } \\
\text { (Schltdl.) H. Rainer }\end{array}$ & Arachichu & Sus frutos se consumen frescos & $\begin{array}{c}\text { (9), (13), (22), } \\
\text { (23) }\end{array}$ & GEN-PRO \\
\hline \multicolumn{5}{|l|}{ APOCYNACEAE } \\
\hline $\begin{array}{l}\text { Araujia odorata (Hook. } \\
\text { \&Arn.) Fontella \& Goyder }\end{array}$ & Tasi(s) & $\begin{array}{l}\text { Llevar sus vástagos atados como } \\
\text { ligas previene las picaduras de } \\
\text { víboras }\end{array}$ & $\begin{array}{l}(3),(9),(20) \\
\quad(22),(23)\end{array}$ & GEN-PRO \\
\hline $\begin{array}{l}\text { Aspidosperma polyneurum } \\
\text { Müll. Arg. }\end{array}$ & Iviraró mí & Se hacen artesanías con su madera & (3), (10), (23) & GEN-PRO \\
\hline $\begin{array}{l}\text { Aspidosperma quebracho- } \\
\text { blanco Schltdl. }\end{array}$ & $\begin{array}{l}\text { Quebracho } \\
\text { blanco }\end{array}$ & $\begin{array}{l}\text { Con su madera se fabrican } \\
\text { armazones y pértigas de carros. } \\
\text { Alergógeno. En veterinaria su } \\
\text { corteza se emplea como vermífugo } \\
\text { y en lavajes contra mataduras }\end{array}$ & $\begin{array}{c}(3),(9),(18) \\
(20),(23), \\
(26)\end{array}$ & UNI \\
\hline $\begin{array}{l}\text { Tabernaemontana } \\
\text { catharinensis A. DC. }\end{array}$ & $\begin{array}{l}\text { Palo de víbora } \\
\text { Zapiranguí o } \\
\text { zapiranquí }\end{array}$ & Su copa atrae los rayos & (3), (23) & UNI \\
\hline \multicolumn{5}{|l|}{ AQUIFOLIACEAE } \\
\hline $\begin{array}{l}\text { Ilex dumosa Reissek var. } \\
\text { guaranina Loes. }\end{array}$ & $\begin{array}{l}\text { Caáminí } \\
\text { (ka'ámirí) }\end{array}$ & $\begin{array}{l}\text { Su madera se emplea para } \\
\text { armazones }\end{array}$ & (6) & GEN-PRO \\
\hline $\begin{array}{l}\text { Ilex paraguariensis A. St.- } \\
\text { Hil.* }\end{array}$ & $\begin{array}{l}\text { Caá, } \\
\text { Yerba mate }\end{array}$ & $\begin{array}{l}\text { Su madera se usa para estatuillas } \\
\text { de santos. Sus semillas contra la } \\
\text { "tristeza" (ver texto) en veterinaria. } \\
\text { Es considerado árbol santo y } \\
\text { propiciador de buena suerte. Volcar } \\
\text { su vástago sobre fuego producía } \\
\text { "aire" o "torcedura" }\end{array}$ & $\begin{array}{l}(3),(6),(9) \\
(12),(23)\end{array}$ & UNI \\
\hline \multicolumn{5}{|l|}{ ARALIACEAE } \\
\hline Hedera helix L.* & Hiedra & $\begin{array}{l}\text { Cultivado como ornamental. } \\
\text { Augura mala suerte }\end{array}$ & (1) & UNI \\
\hline \multicolumn{5}{|l|}{ ARECACEAE } \\
\hline $\begin{array}{l}\text { Acrocomia aculeata (Jacq.) } \\
\text { Lodd. ex Mart. }\end{array}$ & $\begin{array}{l}\text { Coco, } \\
\text { cocotero o } \\
\text { mbocayá }\end{array}$ & $\begin{array}{l}\text { Cultivado. Hojas para textiles y } \\
\text { como techumbre. Mal augurio para } \\
\text { quien lo trasplanta }\end{array}$ & $\begin{array}{c}(1),(9),(22) \\
(23)\end{array}$ & GEN-PRO \\
\hline
\end{tabular}




\begin{tabular}{|c|c|c|c|c|}
\hline $\begin{array}{l}\text { Familia Botánica y nombre } \\
\text { científico }\end{array}$ & $\begin{array}{l}\text { Nombre } \\
\text { vulgar }\end{array}$ & Usos / Significaciones & Bibliografía & Categoría \\
\hline Copernicia alba Morong & $\begin{array}{l}\text { Palma } \\
\text { caranday }\end{array}$ & $\begin{array}{l}\text { Frutos se consumen frescos y } \\
\text { se consideran oleaginosos. Las } \\
\text { cenizas de su estípite como lejía } \\
\text { para mazamorra. Hojas para } \\
\text { cestería y sombreros. Madera para } \\
\text { postes y techumbre }\end{array}$ & (9), (23) & UNI \\
\hline $\begin{array}{l}\text { Trithrinax campestris } \\
\text { (Burmeist.) Drude \& Griseb. }\end{array}$ & $\begin{array}{l}\text { Palma } \\
\text { carandá }\end{array}$ & $\begin{array}{l}\text { Hojas para sombreros. Madera } \\
\text { para construcciones Cenizas de } \\
\text { su estípite se usa como lejía para } \\
\text { elaborar jabón criollo }\end{array}$ & (3) & UNI \\
\hline $\begin{array}{l}\text { Syagrus romanzoffiana } \\
\text { (Cham.) Glassman }\end{array}$ & Palma pindó & $\begin{array}{l}\text { Sus frutos se consumen frescos, } \\
\text { sus hojas para cestería y su madera } \\
\text { para postes y techumbre. En } \\
\text { Domingo de Ramos se queman sus } \\
\text { hojas para evitar caída de rayos. } \\
\text { Quemar sus estípites ocasiona mal } \\
\text { augurio }\end{array}$ & (3), (17), (23) & UNI \\
\hline \multicolumn{5}{|l|}{ ASTERACEAE } \\
\hline $\begin{array}{l}\text { Baccharis salicifolia (Ruiz } \\
\text { \& Pav.) Pers. }\end{array}$ & Chilca & Madera para armazones & $\begin{array}{l}(1),(3),(15) \\
(16),(20) \\
(22)\end{array}$ & GEN-PRO \\
\hline Cirsium vulgare (Savi) Ten. & Cardo lanza & Hojas para textiles & (4) & UNI \\
\hline Helianthus annus L.* & Mirasol & $\begin{array}{l}\text { Cultivado. Su cultivo en el espacio } \\
\text { doméstico augura desgracias }\end{array}$ & (3), (23) & GEN-PRO \\
\hline $\begin{array}{l}\text { Hypochaeris chillensis } \\
\text { (Kunth) Hieron. } \\
\text { Hypochaeris microcephala } \\
\text { (Sch. Bip.) Cabrera }\end{array}$ & $\begin{array}{l}\text { Achicoria } \\
\text { del campo o } \\
\text { silvestre }\end{array}$ & $\begin{array}{l}\text { Sus hojas se consumen crudas en } \\
\text { ensaladas }\end{array}$ & (9), (23) & GEN-PRO \\
\hline $\begin{array}{l}\text { Mikania cordifolia (L.f.) } \\
\text { Willd. }\end{array}$ & $\begin{array}{l}\text { Guaco o } \\
\text { huaco }\end{array}$ & $\begin{array}{l}\text { Sus hojas machacadas se aplican } \\
\text { sobre animales en las picaduras de } \\
\text { víboras }\end{array}$ & $\begin{array}{l}(24),(9) \\
(21),(23)\end{array}$ & GEN-PRO \\
\hline $\begin{array}{l}\text { Pluchea sagittalis (Lam.) } \\
\text { Cabrera }\end{array}$ & $\begin{array}{l}\text { Yerba lucera o } \\
\text { del lucero }\end{array}$ & $\begin{array}{l}\text { Posee entidad espiritual. Participa } \\
\text { en ritual preventivo }\end{array}$ & $\begin{array}{l}(24),(2),(17) \\
(23)\end{array}$ & UNI \\
\hline $\begin{array}{l}\text { Solidago chilensis Meyen, } \\
\text { Solidago microglossa DC. }\end{array}$ & Mbuy & Sus hojas tiñen de amarillo intenso & (22), (23) & GEN-BOT \\
\hline $\begin{array}{l}\text { Tessaria integrifolia Ruiz } \\
\& \text { Pav. }\end{array}$ & Aliso & $\begin{array}{l}\text { Madera para fabricar sillas, } \\
\text { armazones, mesas rústicas, cercos, } \\
\text { jaulas, papel y cartón }\end{array}$ & (3), (15), (23) & UNI \\
\hline Xanthium spinosum $\mathrm{L}$. & Cepacaballo & $\begin{array}{l}\text { Planta entera con sal y ceniza } \\
\text { como antihipsórico en cura mágica } \\
\text { veterinaria (ver texto) }\end{array}$ & $\begin{array}{l}(1),(9),(10), \\
(16),(20) \\
(22),(23)\end{array}$ & UNI \\
\hline \multicolumn{5}{|l|}{ BIGNONIACEAE } \\
\hline $\begin{array}{l}\text { Jacaranda mimosifolia D. } \\
\text { Don }\end{array}$ & Jacarandá & Madera para armazones & (3), (23) & GEN-PRO \\
\hline $\begin{array}{l}\text { Handroanthus heptaphyllus } \\
\text { (Vell.) Mattos }\end{array}$ & Lapacho & $\begin{array}{l}\text { Madera para armazones, ataúdes, } \\
\text { rayos de ruedas y tintura de tejidos }\end{array}$ & $\begin{array}{l}(1),(24),(9) \\
(15),(17) \\
(23)\end{array}$ & GEN-PRO \\
\hline $\begin{array}{l}\text { Tabebuia nodosa (Griseb.) } \\
\text { Griseb. }\end{array}$ & $\begin{array}{l}\text { Toro rataí o } \\
\text { palo cruz }\end{array}$ & Su floración anuncia lluvias & (3), (20), (23) & UNI \\
\hline
\end{tabular}




\begin{tabular}{|c|c|c|c|c|}
\hline $\begin{array}{l}\text { Familia Botánica y nombre } \\
\text { científico }\end{array}$ & $\begin{array}{l}\text { Nombre } \\
\text { vulgar }\end{array}$ & Usos / Significaciones & Bibliografía & Categoría \\
\hline \multicolumn{5}{|l|}{ BOMBACACEAE } \\
\hline $\begin{array}{l}\text { Ceiba insignis (Kunth) P.E. } \\
\text { Gibbs \& Semir, } \\
\text { Ceiba speciosa (A. St.- } \\
\text { Hil., A. Juss. \& Cambess.) } \\
\text { Ravenna }\end{array}$ & $\begin{array}{l}\text { Palo borracho } \\
\text { o samuhú }\end{array}$ & $\begin{array}{l}\text { Su floración anuncia lluvias. } \\
\text { Con sus semillas preparan un } \\
\text { café. Madera para confección de } \\
\text { canoas y construcciones. Fibras } \\
\text { liberianas para cuerdas. Fibras } \\
\text { seminales para hilos de coser. } \\
\text { Poseía entidad espiritual. Se asocia } \\
\text { simbólicamente a su tronco con } \\
\text { alcohólicos }\end{array}$ & $\begin{array}{l}(24),(3),(9) \\
(18),(23) \\
\quad(26)\end{array}$ & BI-UNI \\
\hline \multicolumn{5}{|l|}{ BORAGINACEAE } \\
\hline $\begin{array}{l}\text { Cordia americana (L.) } \\
\text { Gottschling \& J.S. Mill. }\end{array}$ & Guayaibí & $\begin{array}{l}\text { Madera para armazones, mangos } \\
\text { y yugos. Corteza para moldes de } \\
\text { quesos. También "para fibras" }\end{array}$ & $\begin{array}{l}(15),(18) \\
(22),(23) \\
\quad(26)\end{array}$ & UNI \\
\hline \multicolumn{5}{|l|}{ BRASSICACEAE } \\
\hline $\begin{array}{l}\text { Nasturtium officinale W.T. } \\
\text { Aiton, } \\
\text { Rorippa bonariensis (Poir.) } \\
\text { Macloskie }\end{array}$ & Berro & $\begin{array}{l}\text { Sus vástagos se consumen en } \\
\text { ensaladas y sopas }\end{array}$ & (1), (9), (10) & GEN-PRO \\
\hline \multicolumn{5}{|l|}{ CACTACEAE } \\
\hline $\begin{array}{l}\text { Opuntia ficus-indica (L.) } \\
\text { Mill. }\end{array}$ & $\begin{array}{l}\text { Tuna de } \\
\text { Castilla }\end{array}$ & $\begin{array}{l}\text { Hospeda a la cochinilla empleada } \\
\text { para teñir de rojo }\end{array}$ & (19), (20) & UNI \\
\hline \multicolumn{5}{|l|}{ CANNACEAE } \\
\hline $\begin{array}{l}\text { Canna glauca } \mathrm{L} . \\
\text { Canna indica } \mathrm{L} .\end{array}$ & Achira & $\begin{array}{l}\text { Ambas son consideradas plagas de } \\
\text { los cultivos }\end{array}$ & (9), (10), (23) & BI-UNI \\
\hline \multicolumn{5}{|l|}{ CAPRIFOLIACEAE } \\
\hline Lonicera japonica Thunb. & Madreselva & $\begin{array}{l}\text { Cultivado como ornamental. } \\
\text { Auguraba una muerte en la familia } \\
\text { u otra desgracia }\end{array}$ & (9), (10), (23) & GEN-PRO \\
\hline \multicolumn{5}{|l|}{ CARYOPHYLLACEAE } \\
\hline $\begin{array}{l}\text { Dianthus cfr. caryophyllus } \\
\text { L.* }\end{array}$ & $\begin{array}{l}\text { Clavel, clavel } \\
\text { blanco }\end{array}$ & $\begin{array}{l}\text { Cultivado como ornamental. Ritual } \\
\text { para que floreciera (arrancar hojas } \\
\text { al momento de un relámpago) }\end{array}$ & $(24),(9),(23)$ & GEN-PRO \\
\hline \multicolumn{5}{|l|}{ CELTIDACEAE } \\
\hline Celtis spp. & Tala & $\begin{array}{l}\text { Madera para armazones. Sus } \\
\text { frutos se consumen frescos. Poseía } \\
\text { entidad espiritual }\end{array}$ & $\begin{array}{l}(10),(17) \\
(20),(23)\end{array}$ & GEN-BOT \\
\hline \multicolumn{5}{|l|}{ CERVANTESIACEAE } \\
\hline Acanthosyris falcata Griseb. & Iguáhée & Sus frutos se consumen frescos & (3), (23) & GEN-PRO \\
\hline $\begin{array}{l}\text { Jodina rhombifolia (Hook. } \\
\text { \& Arn.) Reissek }\end{array}$ & $\begin{array}{l}\text { Quebracho } \\
\text { flojo, Sombra } \\
\text { de toro }\end{array}$ & Madera para armazones & $\begin{array}{l}(24),(3), \\
(10),(20) \\
(22),(23)\end{array}$ & GEN-PRO \\
\hline \multicolumn{5}{|l|}{ CHENOPODIACEAE } \\
\hline $\begin{array}{l}\text { Bassia scoparia (L.) A.J. } \\
\text { Scott* }\end{array}$ & $\begin{array}{l}\text { Árbol de } \\
\text { Navidad }\end{array}$ & $\begin{array}{l}\text { Suele ser cultivado aunque para } \\
\text { otros es mal augurio }\end{array}$ & (23) & UNI \\
\hline
\end{tabular}




\begin{tabular}{|c|c|c|c|c|}
\hline $\begin{array}{l}\text { Familia Botánica y nombre } \\
\text { científico }\end{array}$ & $\begin{array}{l}\text { Nombre } \\
\text { vulgar }\end{array}$ & Usos / Significaciones & Bibliografía & Categoría \\
\hline $\begin{array}{l}\text { Chenopodium mandonii } \\
\text { (S.Watan.) Aellen } \\
\text { Dysphania ambrosioides } \\
\text { (L.) Mosyakin \& Clemants }\end{array}$ & Paico o caaré & $\begin{array}{l}\text { Cenizas maceradas de sus vástagos } \\
\text { se emplea como lejía para elaborar } \\
\text { jabón criollo }\end{array}$ & $\begin{array}{l}(24),(3),(9), \\
(17),(18), \\
(22),(23)\end{array}$ & GEN-PRO \\
\hline \multicolumn{5}{|l|}{ CONVOLVULACEAE } \\
\hline $\begin{array}{l}\text { Ipomoea carnea Jacq. (Mart. } \\
\text { ex Choisy) D.F. Austin }\end{array}$ & Mandiyurá & $\begin{array}{l}\text { Las cenizas de sus vástagos se usan } \\
\text { como lejía para elaborar jabón } \\
\text { criollo }\end{array}$ & $\begin{array}{l}\text { (3), (9), (20), } \\
\text { (23) }\end{array}$ & UNI \\
\hline \multicolumn{5}{|l|}{ CRASSULACEAE } \\
\hline $\begin{array}{l}\text { Kalanchoe pinnata (Lam.) } \\
\text { Pers.* }\end{array}$ & Maravilla & $\begin{array}{l}\text { Suele ser cultivado como } \\
\text { ornamental aunque para otros es } \\
\text { mal augurio (solteras no se casan) }\end{array}$ & (9), (23) & GEN-PRO \\
\hline \multicolumn{5}{|l|}{ CUCURBITACEAE } \\
\hline $\begin{array}{l}\text { Cucurbita maxima } \\
\text { Duchesne* }\end{array}$ & Zapallo & $\begin{array}{l}\text { Cultivado. Poseía entidad } \\
\text { espiritual. Fruto hervido como } \\
\text { alimento }\end{array}$ & (9), (17), (23) & GEN-PRO \\
\hline \multicolumn{5}{|l|}{ CUPRESSACEAE } \\
\hline Cupressus sempervirens L.* & Ciprés & $\begin{array}{l}\text { Cultivado. Poseía entidad } \\
\text { espiritual. Mal augurio (danzan } \\
\text { duendes por las noches a su } \\
\text { alrededor) }\end{array}$ & $\begin{array}{l}(3),(10) \\
(13),(23)\end{array}$ & GEN-PRO \\
\hline \multicolumn{5}{|l|}{ CYCADACEAE } \\
\hline Cycas revoluta Thunb.* & Cica & $\begin{array}{l}\text { Cultivado como ornamental. Mal } \\
\text { augurio (solteras no se casan) }\end{array}$ & $(23)$ & GEN-PRO \\
\hline \multicolumn{5}{|l|}{ CYPERACEAE } \\
\hline Cyperus giganteus Vahl & Pirí o Junco & Hojas para canastos y persianas & (9), (17), (23) & GEN-PRO \\
\hline Scirpus giganteus Kunth & Paja brava & $\begin{array}{l}\text { Hojas para techumbre. Sus } \\
\text { vástagos en forma de lazos se usan } \\
\text { para curar miasis en vacunos de } \\
\text { manera mágica (ver texto) }\end{array}$ & (3), (17), (23) & GEN-PRO \\
\hline \multicolumn{5}{|l|}{ EUPHORBIACEAE } \\
\hline Manihot esculenta Crantz* & Mandioca & $\begin{array}{l}\text { Cultivado. Con su raíz hervida o } \\
\text { deshidratada se prepara el "popi”, } \\
\text { el "chipá" y almidón. Su corteza } \\
\text { es tóxica para gallinas aunque en } \\
\text { plantaciones se esparcían para } \\
\text { propiciar buena cosecha. Soñar } \\
\text { con sus raíces es augurio de muerte } \\
\text { próxima }\end{array}$ & (3), (9), (23) & UNI \\
\hline Ricinus communis $\mathrm{L}$. & $\begin{array}{l}\text { Ricino } \\
\text { Tártago }\end{array}$ & $\begin{array}{l}\text { Semillas contra la "tristeza" en } \\
\text { veterinaria. Planta oleaginosa. } \\
\text { Poseía entidad espiritual. }\end{array}$ & $\begin{array}{l}(3),(9),(10), \\
(17),(18), \\
(20),(22) \\
(23)\end{array}$ & UNI \\
\hline $\begin{array}{l}\text { Sapium haematospermum } \\
\text { Müll. Arg. } \\
\text { Sapium glandulosum (L.) } \\
\text { Morong }\end{array}$ & Curupí (cay) & $\begin{array}{l}\text { Madera para leña. Su copa atrae los } \\
\text { rayos. Posee entidad espiritual }\end{array}$ & $\begin{array}{l}\text { (3), (9), (15), } \\
\text { (16), (23) }\end{array}$ & GEN-BOT \\
\hline
\end{tabular}




\begin{tabular}{|c|c|c|c|c|}
\hline $\begin{array}{l}\text { Familia Botánica y nombre } \\
\text { científico }\end{array}$ & $\begin{array}{l}\text { Nombre } \\
\text { vulgar }\end{array}$ & Usos / Significaciones & Bibliografía & Categoría \\
\hline \multicolumn{5}{|l|}{ FABACEAE } \\
\hline $\begin{array}{l}\text { Acacia aroma Gillies ex } \\
\text { Hook. \& Arn. } \\
\text { Acacia caven (Molina) } \\
\text { Molina }\end{array}$ & $\begin{array}{l}\text { Aromita, } \\
\text { aromito o } \\
\text { espinillo }\end{array}$ & $\begin{array}{l}\text { Sus flores se usan como } \\
\text { aromatizante. Madera para leña y } \\
\text { postes. Causaba fiebre a quienes } \\
\text { dormían debajo }\end{array}$ & $\begin{array}{l}(9),(10),(18) \\
(22),(23) \\
(26)\end{array}$ & BI-UNI \\
\hline $\begin{array}{l}\text { Acacia bonariensis Gillies } \\
\text { ex Hook. \& Arn. }\end{array}$ & $\begin{array}{l}\text { Yuquery (bu) } \\
\text { zú }\end{array}$ & $\begin{array}{l}\text { Madera para construcciones. Las } \\
\text { cenizas maceradas de sus ramas se } \\
\text { usan como lejía para elaborar jabón } \\
\text { criollo }\end{array}$ & (17), (23) & GEN-PRO \\
\hline $\begin{array}{l}\text { Anadenanthera colubrina } \\
\text { (Vell.) Brenan }\end{array}$ & $\begin{array}{l}\text { Cebil o } \\
\text { curupai }\end{array}$ & $\begin{array}{l}\text { Su corteza como curtiente. Madera } \\
\text { para carpintería }\end{array}$ & $(1),(22),(23)$ & UNI \\
\hline Arachis hypogaea L.* & Maní & $\begin{array}{l}\text { Cultivado. Planta oleaginosa. } \\
\text { Las cáscaras de sus frutos en } \\
\text { plantaciones se arrojan para } \\
\text { propiciar buena cosecha }\end{array}$ & (3), (17), (23) & UNI \\
\hline $\begin{array}{l}\text { Caesalpinia paraguariensis } \\
\text { (D. Parodi) Burkart }\end{array}$ & Guayacán & $\begin{array}{l}\text { Madera para leña, armazones y } \\
\text { sillas. Tintura de tejidos }\end{array}$ & $\begin{array}{l}(5),(9),(15) \\
(18),(20) \\
(22),(23) \\
(26)\end{array}$ & UNI \\
\hline $\begin{array}{l}\text { Chloroleucon tenuiflorum } \\
\text { (Benth.) Barneby \& J.W. } \\
\text { Grimes }\end{array}$ & Tatané & $\begin{array}{l}\text { Madera para artesanías, armazones } \\
\text { y muebles }\end{array}$ & (3), (22) & UNI \\
\hline $\begin{array}{l}\text { Enterolobium } \\
\text { contortisiliquum (Vell.) } \\
\text { Morong }\end{array}$ & Timbó & $\begin{array}{l}\text { Madera para muebles, tablas y } \\
\text { construcciones. Corteza como } \\
\text { curtiente. Fruto hervido para teñir } \\
\text { tejidos }\end{array}$ & $\begin{array}{l}(3),(9),(17) \\
\quad(22),(23)\end{array}$ & GEN-PRO \\
\hline Erythrina crista-galli L. & $\begin{array}{l}\text { Ceibo o } \\
\text { zuiñandy }\end{array}$ & $\begin{array}{l}\text { Corteza como curtiente. Flores, } \\
\text { tallos y hojas para teñir tejidos. Se } \\
\text { usan en ritual funerario (ver texto) }\end{array}$ & $\begin{array}{l}(24),(10) \\
(18),(22) \\
(23),(26)\end{array}$ & UNI \\
\hline $\begin{array}{l}\text { Geoffroea decorticans } \\
\text { (Gillies ex Hook. \& Arn.) } \\
\text { Burkart }\end{array}$ & Chañar & Madera para leña & $\begin{array}{l}(9),(10),(15) \\
(18),(20) \\
(22),(23) \\
(26)\end{array}$ & UNI \\
\hline $\begin{array}{l}\text { Gleditsia amorphoides } \\
\text { (Griseb.) Taub. }\end{array}$ & $\begin{array}{l}\text { Espina }(\text { de) } \\
\text { corona o nuatí } \\
\text { corona }\end{array}$ & Madera para construcciones & $\begin{array}{l}(1),(9),(15) \\
(16),(18) \\
(22),(23) \\
(26)\end{array}$ & UNI \\
\hline Medicago sativa L.* & Alfalfa & $\begin{array}{l}\text { Sus vástagos son forraje del } \\
\text { ganado }\end{array}$ & (3), (9), (23) & UNI \\
\hline Mimosa spp. & Sensitiva & $\begin{array}{l}\text { Si se cerraban sus hojas augura } \\
\text { desgracias }\end{array}$ & (3), (23) & GEN-BOT \\
\hline $\begin{array}{l}\text { Peltophorum dubium } \\
\text { (Spreng.) Taub. }\end{array}$ & Ivirápitá & $\begin{array}{l}\text { Madera para armazones, estructura } \\
\text { y ruedas de carros y artesanías. Su } \\
\text { corteza tiñe de color rojizo }\end{array}$ & (3), (17), (23) & GEN-PRO \\
\hline Prosopis alba Griseb. & Algarrobo & $\begin{array}{l}\text { Madera para construcciones, } \\
\text { cajas de carretas, mesas, sillas y } \\
\text { artesanías. Sus frutos se consumen } \\
\text { frescos. Raíz y resina para teñir de } \\
\text { castaño oscuro. Curtiente }\end{array}$ & (3), (15), (23) & GEN-PRO \\
\hline
\end{tabular}




\begin{tabular}{|c|c|c|c|c|}
\hline $\begin{array}{l}\text { Familia Botánica y nombre } \\
\text { científico }\end{array}$ & $\begin{array}{l}\text { Nombre } \\
\text { vulgar }\end{array}$ & Usos / Significaciones & Bibliografía & Categoría \\
\hline Prosopis kuntzei Harms & Carandá & Madera para construcciones & $(3),(23)$ & UNI \\
\hline $\begin{array}{l}\text { Prosopis nigra (Griseb.) } \\
\text { Hieron. }\end{array}$ & $\begin{array}{l}\text { Algarrobo } \\
\text { negro }\end{array}$ & $\begin{array}{l}\text { Su resina se usa para teñir de negro } \\
\text { y castaño }\end{array}$ & (3), (15), (18) & UNI \\
\hline $\begin{array}{l}\text { Pterogyne nitensTul. } \\
\text { Tipuana tipu (Benth.) } \\
\text { Kuntze* }^{*}\end{array}$ & $\begin{array}{l}\text { Tipa (colorada } \\
\text { y blanca) }\end{array}$ & Madera para armazones & (3), (23) & BI-UNI \\
\hline $\begin{array}{l}\text { Trifolium polymorphum Poir. } \\
\text { Trifolium spp. }\end{array}$ & Trébol & $\begin{array}{l}\text { Todas las especies de este género } \\
\text { en la región son forraje del ganado }\end{array}$ & $\begin{array}{l}(3),(9),(10), \\
(22),(23)\end{array}$ & GEN-PRO \\
\hline \multicolumn{5}{|l|}{ GENTIANACEAE } \\
\hline $\begin{array}{l}\text { Gentianella multicaulis } \\
\text { (Gillies ex Griseb.) Fabris }\end{array}$ & Pasto blanco & $\begin{array}{l}\text { Sus vástagos son forraje de equinos } \\
\text { y mulares }\end{array}$ & (23) & GEN-PRO \\
\hline \multicolumn{5}{|l|}{ GERANIACEAE } \\
\hline $\begin{array}{l}\text { Erodium cicutarium (L.) } \\
\text { L'Hér. ex Aiton }\end{array}$ & Alfilerillo & $\begin{array}{l}\text { Sus vástagos se usan como forraje } \\
\text { del ganado }\end{array}$ & $\begin{array}{l}\text { (1), (3), (10), } \\
\text { (23), }\end{array}$ & GEN-PRO \\
\hline \multicolumn{5}{|l|}{ HALORAGACEAE } \\
\hline $\begin{array}{l}\text { Myriophyllum aquaticum } \\
\text { (Vell.) Verdc. }\end{array}$ & $\begin{array}{l}\text { Espuma de } \\
\text { mar }\end{array}$ & $\begin{array}{l}\text { Cultivado como ornamental. } \\
\text { Para algunos augura infortunio y } \\
\text { desgracias }\end{array}$ & $(3),(23)$ & UNI \\
\hline \multicolumn{5}{|l|}{ HYDRANGEACEAE } \\
\hline $\begin{array}{l}\text { Hydrangea macrophylla } \\
\text { (Thunb.) Ser.* }\end{array}$ & Hortensia & $\begin{array}{l}\text { Cultivado como ornamental, } \\
\text { aunque para otros es mal augurio } \\
\text { (solteras no se casan) }\end{array}$ & (23) & UNI \\
\hline \multicolumn{5}{|l|}{ HYPERICACEAE } \\
\hline Hypericum connatum Lam. & Caabotori/e & $\begin{array}{l}\text { Posee entidad espiritual. Ritual } \\
\text { propiciatorio en Semana Santa (ver } \\
\text { texto) }\end{array}$ & $\begin{array}{l}(1),(24),(8), \\
\quad(9),\end{array}$ & UNI \\
\hline \multicolumn{5}{|l|}{ IRIDACEAE } \\
\hline Iris germanica $\mathrm{L}$. & Lirio & Cultivado como ornamental & (3), (10), (23) & GEN-PRO \\
\hline \multicolumn{5}{|l|}{ LAMIACEAE } \\
\hline $\begin{array}{l}\text { Lavandula angustifolia } \\
\text { Mill.*, Lavandula latifolia } \\
\text { Medik.* } \\
\text { Lavandula officinalis Chaix* }\end{array}$ & Alhucema & $\begin{array}{l}\text { Sus flores se queman como } \\
\text { aromatizante y depurativo del aire. } \\
\text { Flores secas como insectífugo. } \\
\text { Cultivado. } \\
\text { Atraía muertes y desgracias }\end{array}$ & $\begin{array}{l}(24),(3),(9), \\
(10),(23)\end{array}$ & GEN-BOT \\
\hline $\begin{array}{l}\text { Mentha } \mathrm{x} \text { rotundifolia }(\mathrm{L} .) \\
\text { Huds.* }\end{array}$ & Yerba buena & $\begin{array}{l}\text { Sus vástagos se colocan debajo } \\
\text { de almohada en criaturas para } \\
\text { propiciar su bondad }\end{array}$ & $\begin{array}{l}(24),(3),(9), \\
(10),(17), \\
(22),(23)\end{array}$ & GEN-PRO \\
\hline $\begin{array}{l}\text { Pogostemon cablin (Blanco) } \\
\text { Benth.* }\end{array}$ & $\begin{array}{l}\text { Pachulí o } \\
\text { pacholí }\end{array}$ & $\begin{array}{l}\text { Cultivado para propiciar fortuna, } \\
\text { atraer pareja. Sus hojas se usan } \\
\text { para repeler a las polillas }\end{array}$ & $\begin{array}{l}(24),(17) \\
(23)\end{array}$ & GEN-PRO \\
\hline Rosmarinus officinalis L.* & Romero & $\begin{array}{l}\text { Cultivado. Sus vástagos se usan } \\
\text { como condimento. Para otros } \\
\text { augura desgracias }\end{array}$ & $\begin{array}{l}(24),(3),(9) \\
(10),(17) \\
\quad(23)\end{array}$ & UNI \\
\hline \multicolumn{5}{|l|}{ LAURACEAE } \\
\hline $\begin{array}{l}\text { Cinnamomum camphora } \\
\text { (L.) J. Pres1* }\end{array}$ & Alcanfor & $\begin{array}{l}\text { Ritual preventivo contra viruela. Se } \\
\text { usa una pulsera de cuero de zorrino } \\
\text { de la cual cuelga una bolsita con } \\
\text { alcanfor }\end{array}$ & $\begin{array}{l}(1),(3),(9) \\
(10),(25)\end{array}$ & UNI \\
\hline
\end{tabular}




\begin{tabular}{|c|c|c|c|c|}
\hline $\begin{array}{l}\text { Familia Botánica y nombre } \\
\text { científico }\end{array}$ & $\begin{array}{l}\text { Nombre } \\
\text { vulgar }\end{array}$ & Usos / Significaciones & Bibliografía & Categoría \\
\hline $\begin{array}{l}\text { Nectandra angustifolia } \\
\text { (Schrad.) Nees \& Mart. }\end{array}$ & Laurel & $\begin{array}{l}\text { Madera para sillas y cruces } \\
\text { funerarias. Sus hojas se usan en } \\
\text { rituales cada } 24 \text { de junio y } 1^{\circ} \text { de } \\
\text { agosto }\end{array}$ & (3), (5), (23) & GEN-PRO \\
\hline $\begin{array}{l}\text { Ocotea acutifolia } \text { (Nees) } \\
\text { Mez, } \\
\text { Ocotea puberula }(\text { Rich.) } \\
\text { Nees }\end{array}$ & Laurel blanco & Madera para armazones & (9), (23) & BI-UNI \\
\hline \multicolumn{5}{|l|}{ MAGNOLIACEAE } \\
\hline Magnolia grandiflora L.* & Magnolia & $\begin{array}{l}\text { Cultivado. Se considera que su flor } \\
\text { produce "tuberculosis" }\end{array}$ & (23) & GEN-PRO \\
\hline \multicolumn{5}{|l|}{ MALVACEAE } \\
\hline $\begin{array}{l}\text { Gossypium barbadense L.*, } \\
\text { Gossypium hirsutum L.* }\end{array}$ & Algodón & $\begin{array}{l}\text { Cultivado como textil. De su } \\
\text { semilla se extrae un aceite }\end{array}$ & $(3),(23)$ & BI-UNI \\
\hline Sida rhombifolia $\mathrm{L}$. & $\begin{array}{l}\text { Tup(u)icha(tá) } \\
\text { guaycurú o } \\
\text { escoba dura o } \\
\text { del campo }\end{array}$ & $\begin{array}{l}\text { Su floración anuncia lluvias. Ritual } \\
\text { para propiciar la bondad en niños } \\
\text { y curar las miasis en vacunos (ver } \\
\text { texto) }\end{array}$ & $\begin{array}{l}(24),(10) \\
(14),(17) \\
\quad(20)\end{array}$ & GEN-PRO \\
\hline \multicolumn{5}{|l|}{ MARANTACEAE } \\
\hline Thalia geniculata L. & Pahirirí & $\begin{array}{l}\text { Sus hojas se usan como envoltorio } \\
\text { del "chipá" que se cuece bajo las } \\
\text { cenizas }\end{array}$ & (17) & UNI \\
\hline \multicolumn{5}{|l|}{ MELIACEAE } \\
\hline Melia azedarach L.* & Paraíso & $\begin{array}{l}\text { Cultivado. Poseía entidad } \\
\text { espiritual. Si en invierno no perdía } \\
\text { hojas auguraba buen año. Si raíz } \\
\text { llegaba a la casa anunciaba muerte } \\
\text { de jefe de familia. No atraía el rayo }\end{array}$ & $\begin{array}{l}\text { (3), (9), (10), } \\
\text { (17), (22), } \\
\quad(23)\end{array}$ & UNI \\
\hline \multicolumn{5}{|l|}{ MORACEAE } \\
\hline Ficus carica $\mathrm{L} . *$ & Higuera & $\begin{array}{l}\text { Cultivado. Sus frutos se consumen } \\
\text { frescos. Posee entidad espiritual. } \\
\text { Augura infortunios. Ritual para } \\
\text { obtener su "flor de curundú" (ver } \\
\text { texto) }\end{array}$ & $(1),(9)$ & UNI \\
\hline $\begin{array}{l}\text { Ficus luschnathiana (Miq.) } \\
\text { Miq. }\end{array}$ & $\begin{array}{l}\text { Iguápohí o } \\
\text { Ybapoí }\end{array}$ & $\begin{array}{l}\text { Con sus frutos se preparan dulces. } \\
\text { Posee entidad espiritual y su copa } \\
\text { atrae rayos }\end{array}$ & $\begin{array}{l}\text { (3), (9), (17), } \\
\text { (22), (23) }\end{array}$ & GEN-PRO \\
\hline $\begin{array}{l}\text { Morus alba } \mathrm{L} . * \\
\text { Morus nigra } \mathrm{L} . *\end{array}$ & $\begin{array}{l}\text { Morera } \\
\text { (mora) }\end{array}$ & $\begin{array}{l}\text { Cultivado. Sus frutos se consumen } \\
\text { frescos. Posee entidad espiritual. } \\
\text { Mal augurio (solteras no se casan o } \\
\text { muere el jefe de familia) }\end{array}$ & $\begin{array}{l}\text { (7), (9), (10), } \\
\text { (23) }\end{array}$ & GEN-BOT \\
\hline $\begin{array}{l}\text { Sorocea sprucei (Baill.) J.F. } \\
\text { Macbr. }\end{array}$ & Yatitá & Su copa atrae el rayo & (3), (23) & UNI \\
\hline \multicolumn{5}{|l|}{ MUSACEAE } \\
\hline Musa x paradisiaca L.* & Banano & $\begin{array}{l}\text { Cultivado. Posee entidad espiritual. } \\
\text { Ritual propiciatorio para lograr su } \\
\text { fructificación }\end{array}$ & (3), (17), (23) & UNI \\
\hline
\end{tabular}




\begin{tabular}{|c|c|c|c|c|}
\hline $\begin{array}{l}\text { Familia Botánica y nombre } \\
\text { científico }\end{array}$ & $\begin{array}{l}\text { Nombre } \\
\text { vulgar }\end{array}$ & Usos / Significaciones & Bibliografía & Categoría \\
\hline \multicolumn{5}{|l|}{ MYRTACEAE } \\
\hline $\begin{array}{l}\text { Eucalyptus camaldulensis } \\
\text { Dehnh.*, } \\
\text { Eucalyptus globulus Labill.* }\end{array}$ & Eucalipto & $\begin{array}{l}\text { Cultivado. Su copa atrae el rayo. } \\
\text { Ennegrecen sus cabellos con } \\
\text { lavajes de la infusión de sus hojas. } \\
\text { Ritual preventivo el } 1^{\circ} \text { de agosto } \\
\text { (ingestión de su infusión y sahúmo } \\
\text { de casas) }\end{array}$ & (9), (22), (23) & GEN-PRO \\
\hline Eugenia myrcianthes Nied. & $\begin{array}{l}\text { Iguáhai o } \\
\text { ubajay }\end{array}$ & $\begin{array}{l}\text { Sus frutos se comen frescos y en } \\
\text { dulces. Madera para leña }\end{array}$ & $\begin{array}{l}(3),(9),(10), \\
\text { (18), (23), } \\
\text { (26) }\end{array}$ & GEN-PRO \\
\hline $\begin{array}{l}\text { Eugenia uniflora } \mathrm{L} . \\
\text { Eugenia pitanga }(\mathrm{O} . \mathrm{Berg}) \\
\text { Kiaersk. }\end{array}$ & Ñangapirí & Sus frutos se consumen frescos & $\begin{array}{c}(3),(9) \\
(10),(13) \\
(15),(17),(23)\end{array}$ & BI-UNI \\
\hline $\begin{array}{l}\text { Myrcianthes pungens }(\mathrm{O} . \\
\text { Berg) D. Legrand }\end{array}$ & $\begin{array}{l}\text { Guabiyú o } \\
\text { Ivabiyú }\end{array}$ & $\begin{array}{l}\text { Sus frutos se comen frescos. } \\
\text { Madera para construcciones y leña. } \\
\text { Sus hojas se usan en veterinaria } \\
\text { contra granos bucales de los } \\
\text { terneros y en rituales contra fiebre } \\
\text { aftosa }\end{array}$ & $\begin{array}{l}\text { (3), (9), (16), } \\
(17)(22),(23)\end{array}$ & UNI \\
\hline $\begin{array}{l}\text { Plinia trunciflora (O. Berg) } \\
\text { Kausel }\end{array}$ & Iguápurú & $\begin{array}{l}\text { Sus frutos se consumen frescos. } \\
\text { Madera para armazones. Posee } \\
\text { entidad espiritual }\end{array}$ & $\begin{array}{l}(24),(3),(9), \\
(22),(23)\end{array}$ & GEN-PRO \\
\hline Psidium guajaba L.* & $\begin{array}{l}\text { Guayabo o } \\
\text { Arazá }\end{array}$ & $\begin{array}{l}\text { Cultivado. Frutos se comen frescos } \\
\text { y en dulces. Según otros es augurio } \\
\text { de desgracias }\end{array}$ & $\begin{array}{l}\text { (1), (24), (9), } \\
(22),(23)\end{array}$ & GEN-PRO \\
\hline \multicolumn{5}{|l|}{ NYCTAGINACEAE } \\
\hline $\begin{array}{l}\text { Pisonia zapallo Griseb. var. } \\
\text { guaranitica Toursark. }\end{array}$ & $\begin{array}{l}\text { Francisco } \\
\text { Álvarez }\end{array}$ & Madera para armazones & $\begin{array}{l}\text { (3), (9), (15), } \\
(20),(23)\end{array}$ & GEN-PRO \\
\hline \multicolumn{5}{|l|}{ PASSIFLORACEAE } \\
\hline Passiflora caerulea L. & $\begin{array}{l}\text { Mburucuyá, } \\
\text { Pasionaria }\end{array}$ & $\begin{array}{l}\text { Cultivado. Sus frutos se consumían } \\
\text { frescos. Según algunos augura } \\
\text { riñas matrimoniales }\end{array}$ & $\begin{array}{l}(24),(3),(9) \\
(10),(17) \\
\quad(23)\end{array}$ & GEN-PRO \\
\hline \multicolumn{5}{|l|}{ PHYTOLACCACEAE } \\
\hline Phytolacca dioica $\mathrm{L}$. & Ombú & $\begin{array}{l}\text { Madera para leña. Rituales } \\
\text { terapéuticos contra miasis y } \\
\text { hernias equinas (ver texto). Su } \\
\text { copa atrae el rayo. Posee entidad } \\
\text { espiritual. Augura el infortunio } \\
\text { para la familia. Malos influjos para } \\
\text { quienes duermen a su sombra }\end{array}$ & $\begin{array}{l}(3),(10), \\
(14),(17), \\
(22),(23)\end{array}$ & GEN-PRO \\
\hline \multicolumn{5}{|l|}{ PLANTAGINACEAE } \\
\hline $\begin{array}{l}\text { Plantago tomentosa Lam. } \\
\text { ssp. tomentosa }\end{array}$ & Llantén & $\begin{array}{l}\text { Sus hojas en lavajes sirve como } \\
\text { vulnerario en veterinaria }\end{array}$ & $\begin{array}{l}\text { (24), (5), (9), } \\
\quad(17)\end{array}$ & GEN-PRO \\
\hline \multicolumn{5}{|l|}{ POACEAE } \\
\hline Arundo donax $\mathrm{L}$. & Caña hueca & Forraje para ganado & (20) & UNI \\
\hline Cenchrus echinatus L. & Cadillo & $\begin{array}{l}\text { Forraje para ganado. Se considera } \\
\text { maleza de cultivos }\end{array}$ & $\begin{array}{c}\text { (9), }(20),(22) \text {, } \\
(23)\end{array}$ & BI-UNI \\
\hline Cenchrus spinifex Cav. & Cadillito & $\begin{array}{l}\text { Forraje para ganado. Se considera } \\
\text { maleza de cultivos }\end{array}$ & $(23)$ & UNI \\
\hline
\end{tabular}




\begin{tabular}{|c|c|c|c|c|}
\hline $\begin{array}{l}\text { Familia Botánica y nombre } \\
\text { científico }\end{array}$ & $\begin{array}{l}\text { Nombre } \\
\text { vulgar }\end{array}$ & Usos / Significaciones & Bibliografía & Categoría \\
\hline $\begin{array}{l}\text { Digitaria sanguinalis (L.) } \\
\text { Scop. }\end{array}$ & Pasto colchón & $\begin{array}{l}\text { Sus vástagos son forraje para el } \\
\text { ganado }\end{array}$ & (3), (23) & GEN-PRO \\
\hline \multirow[t]{2}{*}{$\begin{array}{l}\text { Elionurus muticus (Spreng.) } \\
\text { Kuntze }\end{array}$} & Aibe & $\begin{array}{l}\text { Sus vástagos son forraje de equinos } \\
\text { y mulares }\end{array}$ & $\begin{array}{c}(3),(15),(20) \\
(23)\end{array}$ & UNI \\
\hline & Espartillo & $\begin{array}{l}\text { Sus hojas se usan en rituales } \\
\text { terapéuticos contra miasis del } \\
\text { ganado. Sus vástagos son forraje } \\
\text { para equinos y mulares }\end{array}$ & $\begin{array}{l}(17),(20) \\
\quad(23)\end{array}$ & GEN-PRO \\
\hline $\begin{array}{l}\text { Guadua chacoensis (Rojas) } \\
\text { Londoño \& P.M. Peterson, } \\
\text { Guadua trinii (Nees) Nees } \\
\text { ex Rupr. }\end{array}$ & Tacuara & $\begin{array}{l}\text { Sus cañas se usan para cercos y } \\
\text { cielorrasos. Si estas se queman } \\
\text { augura la pobreza }\end{array}$ & $\begin{array}{l}\text { (7), (9), (10), } \\
\quad(18),(23), \\
\quad(26)\end{array}$ & GEN-PRO \\
\hline $\begin{array}{l}\text { Guadua chacoensis (Rojas) } \\
\text { Londoño \& P.M. Peterson }\end{array}$ & Tacuaruzú & Sus cañas se usan para cercos & (3), (7), (23) & GEN-PRO \\
\hline Guadua paraguayana Döll & Picanilla & $\begin{array}{l}\text { Si se queman sus cañas augura } \\
\text { pobreza. Cenizas en fricciones para } \\
\text { propiciar que los niños caminen } \\
\text { pronto }\end{array}$ & (3), (23) & UNI \\
\hline $\begin{array}{l}\text { Merostachys clausseni } \\
\text { Munro }\end{array}$ & Tacuapí & Tallo para canastos y cercos. & (3), (7), (23) & GEN-PRO \\
\hline Paspalum dilatatum Poir. & Pasto dulce & $\begin{array}{l}\text { Sus vástagos son forraje para } \\
\text { ganado }\end{array}$ & (3), (23) & GEN-PRO \\
\hline $\begin{array}{l}\text { Cenchrus pilcomayensis } \\
\text { (Mez) Morrone }\end{array}$ & Simbol & $\begin{array}{l}\text { Sus vástagos se emplean para } \\
\text { canastas, cestas y como forraje } \\
\text { vacuno. Sus tallos para paredes y } \\
\text { techumbre }\end{array}$ & (3), (20), (23) & GEN-PRO \\
\hline $\begin{array}{l}\text { Trichloris pluriflora } \mathrm{E} . \\
\text { Fourn. }\end{array}$ & Pasto crespo & $\begin{array}{l}\text { Sus vástagos son forraje de equinos } \\
\text { y mulares }\end{array}$ & (3), (11), (23) & GEN-BOT \\
\hline Zea mays L.* & Maíz & $\begin{array}{l}\text { Cultivado. Sus frutos se comen } \\
\text { hervidos. Sus cenizas rinden una } \\
\text { lejía para elaborar jabón criollo. } \\
\text { Participa en rituales terapéuticos } \\
\text { (contra garrapatas y moquillo } \\
\text { canino) y preventivos (preservar } \\
\text { sembradíos). Relato mítico sobre } \\
\text { su origen (ver texto) }\end{array}$ & (9), (23) & UNI \\
\hline \multicolumn{5}{|l|}{ PONTEDERIACEAE } \\
\hline $\begin{array}{l}\text { Eichhornia azurea (Sw.) } \\
\text { Kunth, } \\
\text { Eichhornia crassipes (Mart.) } \\
\text { Solms }\end{array}$ & Camalote & $\begin{array}{l}\text { Constituyen forrajes para todo tipo } \\
\text { de ganado }\end{array}$ & $\begin{array}{l}(1),(24),(15) \\
(20)\end{array}$ & GEN-PRO \\
\hline \multicolumn{5}{|l|}{ PORTULACACEAE } \\
\hline Portulaca oleracea $\mathrm{L}$. & Verdolaga & $\begin{array}{l}\text { Sus vástagos son forraje de } \\
\text { porcinos }\end{array}$ & $\begin{array}{l}(3),(9),(10), \\
(17),(18) \\
(23),(26)\end{array}$ & GEN-PRO \\
\hline \multicolumn{5}{|l|}{ PRIMULACEAE } \\
\hline $\begin{array}{l}\text { Myrsine laetevirens (Mez) } \\
\text { Arechav. }\end{array}$ & Canelón & $\begin{array}{l}\text { Madera para construcciones. Sus } \\
\text { vástagos incinerados rinden una } \\
\text { lejía para elaborar jabón criollo }\end{array}$ & $\begin{array}{l}(15),(18) \\
\quad(23)\end{array}$ & GEN-PRO \\
\hline Primula spp.* & Primavera & "Sirve para hacer tatuajes" & $(10),(23)$ & GEN-PRO \\
\hline
\end{tabular}




\begin{tabular}{|c|c|c|c|c|}
\hline $\begin{array}{l}\text { Familia Botánica y nombre } \\
\text { científico }\end{array}$ & $\begin{array}{l}\text { Nombre } \\
\text { vulgar }\end{array}$ & Usos / Significaciones & Bibliografía & Categoría \\
\hline \multicolumn{5}{|l|}{ RHAMNACEAE } \\
\hline $\begin{array}{l}\text { Sarcomphalus mistol } \\
\text { (Griseb.) Hauenschild }\end{array}$ & Mistol & $\begin{array}{l}\text { Madera para armazones. Se } \\
\text { considera que su copa nunca atrae } \\
\text { los rayos }\end{array}$ & $\begin{array}{l}\text { (3), (10), (20), } \\
\text { (18), (22) } \\
\text { (23) }\end{array}$ & UNI \\
\hline \multicolumn{5}{|l|}{ ROSACEAE } \\
\hline Prunus persica (L.) Batsch* & Duraznero & $\begin{array}{l}\text { Cultivado. Sus frutos se comen } \\
\text { frescos. Ritual propiciatorio para } \\
\text { lograr su fructificación. Sus hojas } \\
\text { se usan contra miasis en veterinaria }\end{array}$ & $\begin{array}{l}(1),(3),(9) \\
(10),(23)\end{array}$ & UNI \\
\hline \multirow[t]{2}{*}{ Rosa chinensis Jacq.* } & Rosa (blanca) & $\begin{array}{l}\text { Cultivado. Para algunos es de mal } \\
\text { augurio }\end{array}$ & $(9),(23)$ & GEN-PRO \\
\hline & $\begin{array}{l}\text { Siete } \\
\text { hermanas }\end{array}$ & $\begin{array}{l}\text { Cultivado. Para algunos augura } \\
\text { separación familiar }\end{array}$ & (9) & UNI \\
\hline Spiraea cantoniensis Lour.* & $\begin{array}{l}\text { Corona de } \\
\text { novia }\end{array}$ & $\begin{array}{l}\text { Cultivado. Para algunos es de mal } \\
\text { augurio (solteras no se casan) }\end{array}$ & (23) & UNI \\
\hline \multicolumn{5}{|l|}{ RUTACEAE } \\
\hline Citrus aurantifolia Swingle* & Lima & $\begin{array}{l}\text { Cultivado. Sus frutos se consumen } \\
\text { frescos. Participa en rituales } \\
\text { preventivos (para ahuyentar } \\
\text { víboras y maleficios) (ver texto) }\end{array}$ & $(3),(23)$ & UNI \\
\hline Citrus limon (L.) Osbeck * & $\begin{array}{l}\text { Limón, } \\
\text { Limón real }\end{array}$ & $\begin{array}{l}\text { Su jugo con sal y vinagre contra } \\
\text { fiebre aftosa }\end{array}$ & $\begin{array}{l}\text { (3), (9), (10), } \\
\text { (13), (23) }\end{array}$ & UNI \\
\hline Citrus sinensis (L.) Osbeck* & Naranjo & $\begin{array}{l}\text { Cultivado. Sus frutos se comen } \\
\text { frescos }\end{array}$ & $\begin{array}{l}\text { (3), }(9),(10) \\
(23)\end{array}$ & UNI \\
\hline Ruta chalepensis L.* & Ruda & $\begin{array}{l}\text { Cultivado con fines preventivos } \\
\text { (de desgracias y maleficios) y } \\
\text { propiciatorio (prosperidad y } \\
\text { felicidad). Posee entidad espiritual. } \\
\text { Si se seca augura miseria y ruina. } \\
\text { El } 1^{\circ} \text { de agosto se toma en té o con } \\
\text { caña en ritual preventivo }\end{array}$ & $\begin{array}{l}\text { (3), }(24),(9) \text {, } \\
\quad(23)\end{array}$ & UNI \\
\hline \multicolumn{5}{|l|}{ SALICACEAE } \\
\hline $\begin{array}{l}\text { Populus deltoides } \mathrm{W} . \\
\text { Bartram ex Marshall* } \\
\text { Populus nigra L.* }\end{array}$ & $\begin{array}{l}\text { Álamo } \\
\text { Álamo negro }\end{array}$ & $\begin{array}{l}\text { Cultivado. Posee entidad espiritual. } \\
\text { Para algunos augura la ruina }\end{array}$ & $\begin{array}{l}\text { (1), (3), (10), } \\
\quad(23)\end{array}$ & $\begin{array}{l}\text { GEN-BOT } \\
\text { UNI }\end{array}$ \\
\hline Salix babylonica L.* & Sauce llorón & $\begin{array}{l}\text { Cultivado. Anuncia lluvias si sus } \\
\text { ramas se agitan. Para algunos } \\
\text { augura desgracias }\end{array}$ & $(3),(23)$ & UNI \\
\hline Salix humboldtiana Willd. & Sauce & $\begin{array}{l}\text { Madera para armazones, cercos, } \\
\text { jaulas, mesas y sillas. Su corteza } \\
\text { incinerada se emplea para } \\
\text { oftalmias en veterinaria. Posee } \\
\text { entidad espiritual }\end{array}$ & $\begin{array}{l}(3),(9),(17) \\
(22),(23)\end{array}$ & GEN-PRO \\
\hline \multicolumn{5}{|l|}{ SAPOTACEAE } \\
\hline $\begin{array}{l}\text { Chrysophyllum gonocarpum } \\
\text { (Mart. \& Eichler) Engl. }\end{array}$ & Aguaí & $\begin{array}{l}\text { Sus frutos se consumen frescos } \\
\text { o como dulces. Madera para } \\
\text { construcciones. Su resina como } \\
\text { aromatizante }\end{array}$ & $\begin{array}{l}(17),(22) \\
\quad(23)\end{array}$ & UNI \\
\hline
\end{tabular}




\begin{tabular}{|c|c|c|c|c|}
\hline $\begin{array}{c}\text { Familia Botánica y nombre } \\
\text { científico }\end{array}$ & $\begin{array}{l}\text { Nombre } \\
\text { vulgar }\end{array}$ & Usos / Significaciones & Bibliografía & Categoría \\
\hline $\begin{array}{l}\text { Sideroxylon obtusifolium } \\
\text { (Roem. \& Schult.) T.D. } \\
\text { Penn. }\end{array}$ & Ivirávirá & Madera para armazones & $(3),(18)$ & UNI \\
\hline \multicolumn{5}{|l|}{ SOLANACEAE } \\
\hline Brunfelsia australis Benth.* & $\begin{array}{l}\text { Jazmín } \\
\text { paraguayo } \\
\text { Azucena del } \\
\text { campo o del } \\
\text { monte }\end{array}$ & $\begin{array}{l}\text { Cultivado. Augura ruina y } \\
\text { desgracias }\end{array}$ & $\begin{array}{l}(3),(22),(23) \\
(23)\end{array}$ & $\begin{array}{l}\text { GEN-PRO } \\
\text { UNI }\end{array}$ \\
\hline Cestrum parqui L’Hér. & $\begin{array}{l}\text { Duraznillo o } \\
\text { hediondilla }\end{array}$ & $\begin{array}{l}\text { Sus vástagos se emplean en rituales } \\
\text { terapèuticos (contra heridas y el } \\
\text { "aire") en veterinaria (ver texto) }\end{array}$ & $\begin{array}{l}(1),(15),(10) \\
\quad(20),(22)\end{array}$ & UNI \\
\hline Nicotiana glauca Graham & Palán palán & $\begin{array}{l}\text { Sus ramas se usan para paredes y } \\
\text { techumbre }\end{array}$ & $\begin{array}{l}(3),(9),(10) \\
(20),(22) \\
\quad(23)\end{array}$ & UNI \\
\hline Nicotiana tabacum L.* & Tabaco & $\begin{array}{l}\text { Cultivado. No debían cosecharlo } \\
\text { quienes tuvieran dolor de cintura. } \\
\text { Sus tallos se usan en lavajes contra } \\
\text { mataduras en veterinaria }\end{array}$ & $\begin{array}{l}(3),(9),(17) \\
\quad(22),(23)\end{array}$ & UNI \\
\hline \multicolumn{5}{|l|}{ TYPHACEAE } \\
\hline Typha domingensis Pers. & Totora o pirí & $\begin{array}{l}\text { Sus hojas se usan para esteras, } \\
\text { asientos, jergones, piolas y } \\
\text { techumbre. Sus vástagos como } \\
\text { forraje de equinos y mulares. Sus } \\
\text { flores son melíferas }\end{array}$ & (9), (17), (23) & GEN-PRO \\
\hline \multicolumn{5}{|l|}{ ULMACEAE } \\
\hline $\begin{array}{l}\text { Phyllostylon rhamnoides (J. } \\
\text { Poiss.) Taub. }\end{array}$ & Palo lanza & Madera para construcciones & $(3),(23)$ & UNI \\
\hline
\end{tabular}

*: Exótica no asilvestrada. Bibliografía usada para correspondencias: (1) Amorín (1988), (2) Cazes Camarero (2000), (3) De la Peña \& Pensiero (2004), (4) Gobierno de México (2017), (5) Hassler (1909), (6) Keller et al. (2016), (7) Martínez Crovetto† (2012), (8) Martínez (2010), (9) Martínez Crovetto (1981a), (10) Montesano (1913), (11) Morello \& Saravia Toledo (1959), (12) Parodi (1886), (13) Dimitri (1987), (14) Pennington (1904), (15) Pensiero et al. (2005), (16) Petetín \& Marzocca (1984), (17) Pirondo (2016), (18) Rosso \& Scarpa (2012), (19) Scarpa (2004), (20) Scarpa (2012), (21) Scarpa \& Anconatani (2017), (22) Scarpa et al. (2016), (23) Schulz (1976), (24) Schulz† (1997), (25) Tropicos.org (2017), (26) Wernicke (1944). Categoría: UNI: Correspondencia unívoca, BI-UNI: Correspondencia biunívoca, GEN: Genérico no prototípico, GEN-PRO: Genérico prototípico, GEN-BOT: Genérico = género botánico.

Tabla 2. Cuantificaciones resultantes del proceso de estimación de las identidades botánicas.

Table 2. Quantifications resulting from the process of estimating botanical identities.

\begin{tabular}{|cccc|}
\hline $\begin{array}{c}\text { Correspondencias nombre vulgar / } \\
\text { nombre científico }\end{array}$ & \# Nombres vulgares & \# Taxa botánicos & Citas bibliográficas \\
Total no depuradas & 337 & $>308$ & 1565 \\
Total depuradas & 294 & 308 & 1137 \\
Depuradas no medicinales & 183 & 168 & 543 \\
\hline
\end{tabular}


fue registrado por un solo informante. Dada la gran cantidad de datos totales registrados y a fin de no excedernos en la extensión de este trabajo, solo se describen y analizan a continuación los usos no-medicinales de las plantas. Debido a su abundancia y diversidad, los datos de empleo medicinal serán abordados en una futura publicación.

En total se registraron 428 datos etnobotánicos no-medicinales asignados a 168 taxa referidos bajo un n.v. con identificación botánica plausible, a lo largo de 818 reportes totales (Tabla 1). En la Fig. 3 se grafica la participación porcentual de las categorías de uso no-medicinales halladas en la ENF. En la Tabla 3 se enlista la cantidad de taxa vegetales así como las frecuencias absolutas y porcentajes de los datos etnobotánicos totales de la ENF para cada una de las categorías no-medicinales consideradas. Respecto a la categoría "religiosidad popular", casi la mitad de las significaciones específicas totales $(48,3 \%)$ alude o bien a la condición de "mal augurio" de la planta (34 datos sobre 34 taxa), o a las que poseen cierta entidad espiritual conocida como "porá" (24 datos sobre 24 taxa). En el primer caso, la presencia de estas plantas es caracterizada como nefasta ya que suele anunciar algún tipo de desgracia, tal como la muerte, la soltería -en dicho contexto socio-histórico-, la desunión familiar o conyugal, el infortunio, la pobreza o bien atraer alguna enfermedad -entre otras-, lo cual suele referirse en el discurso bajo la forma de un "castigo". Un ejemplo de esto último lo ilustra el dicho popular de la región: "casa con ombú acaba en tapera" (Gelasio Acosta, La Zulema, Pcia. de Santa Fe, Legajo $n^{\circ} 3$ ).

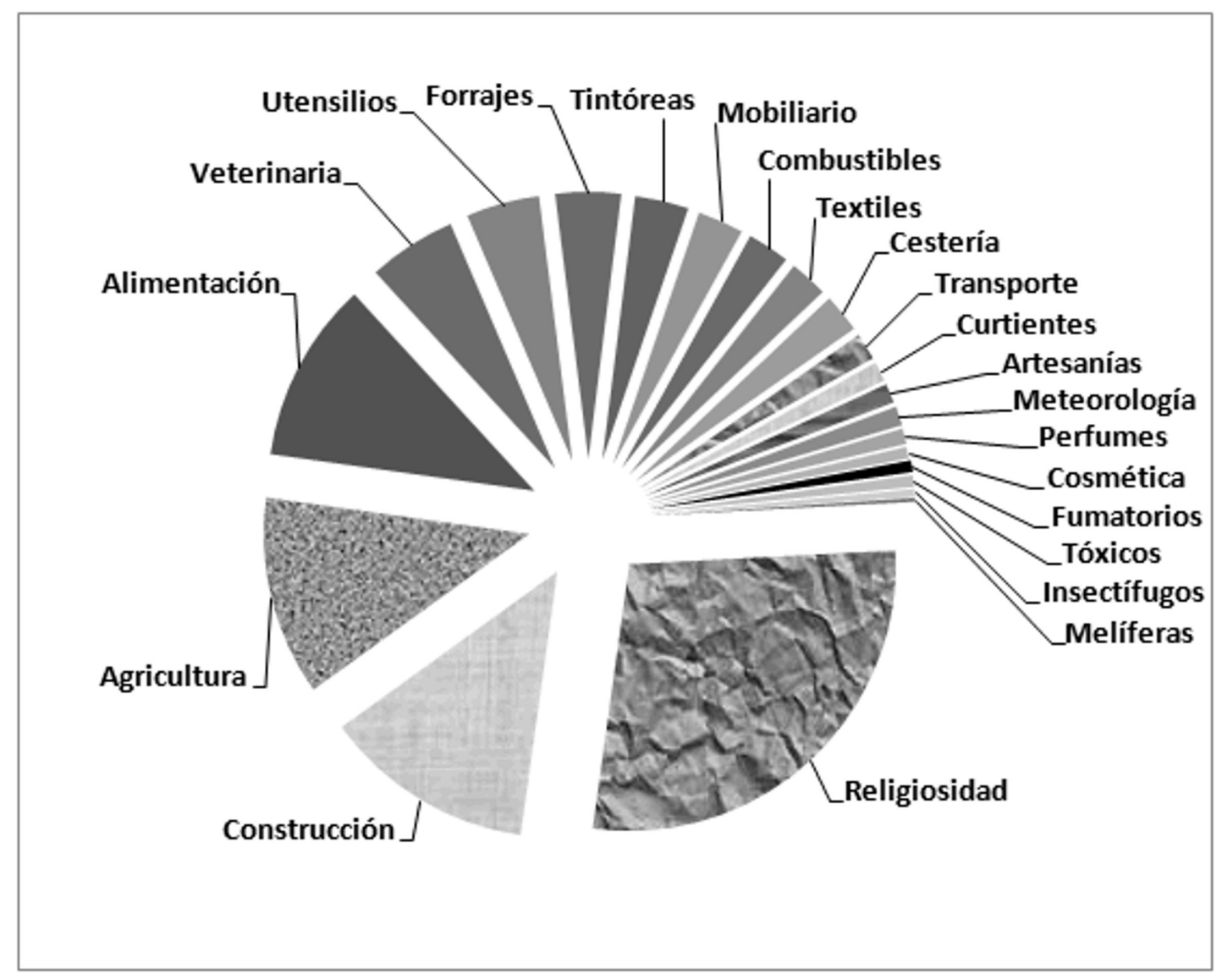

Fig. 3. Principales categorías de usos de las plantas.

Fig. 3. Main categories of plant uses. 
G. F. Scarpa \& C. N. Rosso, Etnobotánica no-médica criolla en Encuesta Nacional de Folklore de 1921

Tabla 3. Categorías de uso no-medicinales de las plantas.

Table 3. Categories of non-medicinal plant uses.

\begin{tabular}{|cccc|}
\hline Categoría de uso & \# De aplicaciones & \# Taxa vegetales & \% Aplicaciones \\
\hline Religiosidad popular & 120 & 78 & 9,5 \\
Construcciones & 55 & 47 & 4,36 \\
\hline Agricultura & 52 & 52 & 4,12 \\
\hline Alimentos & 47 & 38 & 3,73 \\
\hline Veterinaria & 23 & 17 & 1,82 \\
\hline Utensilios & 19 & 16 & 1,50 \\
\hline Forrajes & 17 & 17 & 1,35 \\
Tintóreas & 14 & 13 & 1,11 \\
\hline Mobiliario & 12 & 8 & 0,95 \\
Combustible & 11 & 10 & 0,87 \\
\hline Textiles & 10 & 8 & 0,79 \\
Cestería & 10 & 7 & 0,79 \\
Transporte & 7 & 6 & 0,55 \\
Curtientes & 5 & 5 & 0,39 \\
\hline Artesanías & 5 & 5 & 0,39 \\
Meteorología & 5 & 5 & 0,39 \\
\hline Perfumes & 4 & 4 & 0,31 \\
\hline Funebria & 3 & 3 & 0,24 \\
Tóxicas & 3 & 3 & 0,24 \\
Cosmética & 3 & 3 & 0,24 \\
\hline Insectífugas & 2 & 2 & 0,16 \\
\hline Melíferas & 1 & 1 & 0,08 \\
TOTALES & $\mathbf{4 2 8}$ & & $\mathbf{3 3 . 9 0}$ \\
\hline
\end{tabular}

Es por dicha significación que los criollos del Chaco Húmedo se previenen de cultivar las plantas así caracterizadas en sus casas, entre otras interdicciones.

Respecto a las plantas referidas por poseer "porá"4 pudimos interpretar, a partir del discurso de los encuestados, que serían aquellas que albergan entidades espirituales -ya sean almas de los muertos o "dueños" de las especies vegetales- de naturaleza maligna

\footnotetext{
${ }^{4}$ Colombres (2012) afirma que, según la cosmovisión guaraní, el "angá" (aliento, soplo o alma) de los que mueren sufre una transformación ontológica en "póra" y comienza a rondar los lugares familiares sembrando el terror.
}

y nefasta, las cuales suelen hallarse escondidas dentro de los árboles. Las mismas podrían -según los encuestados- adoptar la forma de burros, serpientes, caballos, "cerdos sin cabezas", llamaradas, mujeres jóvenes o "duendes" y danzar alrededor de tales árboles emitiendo gemidos o quejidos durante la hora de la siesta, en noches tempestuosas o los días martes. Por ejemplo, el "ombú" (Phytolacca dioica L.) fue referido como una planta que "tiene dueño" o bien que albergaba "almas en pena" o "fantasmas", por lo que no había que pasar ni silbar en sus cercanías.

El empleo de vegetales en rituales propiciatorios también resultó significativo (con 15 taxa, 15 datos), especialmente 
para obtener una buena cosecha o bien la "misteriosa flor del curundú". A partir de la lectura comprensiva y análisis de los legajos consultados pudimos interpretar que los vocablos "curundú", "payé" y "reliquia" son empleados en el discurso del criollo del Chaco Húmedo de manera indistinta para referirse a especies de amuletos con usos preventivos, propiciatorios o dañinos. Dicha "flor"correspondería a una entidad ideal (de naturaleza no empírica) de color blanco y de mediano tamaño que brotaría de las "higueras" -Ficus carica L.-, "doradillas" -Anemia tomentosa (Savigny) Sw. y Hemionitis tomentosa (Lam.) Raddi- y del "caa botori"-Hypericum connatum Lam.-, solamente durante la víspera del Viernes Santo o del día de San Juan. Según los encuestados, para lograr obtener la "flor del curundú" se debería limpiar alrededor de la planta el día de Jueves Santo, colocar un paño blanco de seda sobre el suelo, prenderle velas a su alrededor y pedir aquello que se procura ("el deseo"). Varios docentes registraron relatos acerca de "apariciones" (fantasmas, animales policéfalos y víboras) durante la madrugada del Viernes Santo cuya finalidad consistiría en impedir que quien lleva a cabo dicho ritual desista de su cometido, hasta el extremo de llegar a provocarle su muerte. Sin embargo, su posesión era muy valorada para tener fortuna en el juego de naipes, de la taba o para conquistar mujeres.

El empleo de vegetales en rituales preventivos involucra 15 taxones (12 datos) destinados a evitar brujerías, maleficios, enfermedades, heladas que dañen los cultivos, caída de rayos y la acción de entidades malignas ("porá"). En todos los casos estas prácticas están asociadas a tiempos y/o espacios particularmente calificados, ya que se llevan a cabo durante el $1^{\circ}$ de agosto (denominado "mes de los muertos"), Viernes Santo o Domingo de Ramos y en encrucijadas de caminos o sembradíos. Un caso significativo lo constituye la "palma" (Syagrus romanzoffiana (Cham.) Glassman), cuyo estípite no debe ser quemado "porque los ángeles la llevan en la mano y Dios se enojaría si lo hicieran" (Enriqueta Cayré, Colonia Benítez, Pcia. del Chaco, Legajo $\mathrm{n}^{\mathrm{o}} 37$ ), mientras que sus hojas -que se bendicen durante el Domingo de Ramos- sí deben ser incineradas para prevenirse de los rayos. Por último, otras significaciones de las plantas asociadas a las creencias de los criollos del Chaco Húmedo aluden a sus propiedades de atraer o evitar los rayos (10 datos), de producir enfermedades o malestares de diversa índole (8), de buen augurio (5) y de ahuyentar víboras (3), entre otras menos representadas.

Las aplicaciones vegetales referidas a la categoría "construcciones" ocupan el segundo lugar de los usos no-medicinales con 55 aplicaciones totales (47 taxa). Entre éstas se destacan las relativas a erigir viviendas (32 datos), especialmente para su estructura (20) y en menor cantidad para techumbre (7), paredes y cielorrasos. Los demás usos (23) de las plantas en esta categoría se refieren a otros tipos de construcciones y a la confección de cercos y postes.

En tercer lugar, bajo la categoría "agricultura" (52 datos, 52 taxa) se agrupan mayormente plantas cultivadas (49) de procedencia exótica (40), usadas como alimenticias y ornamentales. Las restantes corresponden a plantas nativas o asilvestradas cultivadas principalmente con fines medicinales $\mathrm{y}$, en menor medida, como ornamentales. Por último, tres taxa son considerados como "malezas", ya que se consignan como plagas para los cultivos.

Entre los usos alimenticios (47) la mayoría de los taxa involucrados (38) se emplean en la forma de frutos frescos (22), mientras que el resto corresponde a diversas partes vegetales empleadas en una variada gama de preparaciones (hervido, tostado, como hortalizas, oleaginosas, en dulces, sopas, etc.). Entre estos últimos se destaca el empleo de la "mandioca" en numerosas preparaciones incluido el "popi" (mandioca seca deshidratada) y el "chipá", típicos platos de la cocina litoraleña de raíz guaranítica.

En quinto lugar de importancia de acuerdo al número de usos (23) se ubican las plantas (17 taxa) empleadas en medicina veterinaria. Se utilizan para 15 tipos de indicaciones terapéuticas, la más importante de las cuales es como antimiásico, para la cual se prescriben 5 taxa diferentes. La mayoría de estos usos corresponden a verdaderos rituales terapéuticos (no naturalísticos) consistentes en representar simbólicamente el acto mismo de la "cura" 
del trastorno, a través de nudos que se cierran sobre la afección, collares confeccionados con marlos que se descuelgan del cogote del animal, la cicatrización de heridas infligidas sobre una planta con la forma del rastro del enfermo o bien el arrojar hacia atrás bolsas con granos que simbolizan la afección. También se practica la "cura de palabra" consistente en la pronunciación de rezos mientras se realizan gestos en forma de cruz con los brazos munidos de ramilletes de ciertos vegetales.

De los 19 usos registrados en la categoría "utensilios" (que involucra 16 taxa) la mayoría de ellos (10) corresponde a partes aéreas que son incineradas y maceradas en agua durante 24 horas para emplearse como sales alcalinas ("lejías"), para la elaboración de jabones. Esta solución es agregada a la grasa vacuna para luego someterse a un calentamiento prolongado (durante el cual debe revolverse el preparado) hasta concluir el proceso de saponificación de toda la mezcla.

Las demás categorías de usos no-medicinales involucran una menor cantidad de aplicaciones totales, por lo que no ameritan aquí descripción o análisis comparable a las anteriormente abordadas.

\section{Discusión}

La dilucidación de las correspondencias existentes entre la nomenclatura vernácula y la identificación taxonómica de las plantas constituye una de las primeras labores que debe realizarse en toda investigación etnobotánica, antes de adscribir los usos y significaciones que un pueblo refiere para cada taxón. Consideramos aquí que, dado el carácter histórico de este trabajo, resulta plausible homologar esta primera fase de la investigación a la consulta bibliográfica efectuada en este trabajo acerca de tales correspondencias, debido a que estas últimas se efectuaron sobre la base de documentación botánica referida por otros autores respecto a la fitonimia del mismo grupo humano. Otros motivos por los cuales este proceso de homologación se hallaría justificado se vinculan a la relevancia de los resultados de este estudio. En efecto, el volumen y calidad de los datos registrados en la ENF, la originalidad de los mismos -en virtud de la inexistencia de estudios etnobotánicos sobre los criollos del Chaco Húmedo- y su condición histórica que implica la imposibilidad de su registro en la actualidad, también serían argumentos que sustentan el procedimiento empleado para la estimación de las identidades taxonómicas.

En su estudio sobre la ENF, Arovich de Bogado (2005) señala la necesidad de contar con los contextos de producción y de interpretación de los datos históricos para un cabal análisis de los mismos. Concordamos con la autora en la imposibilidad de reponer actualmente los ámbitos de producción de donde provienen los datos de la ENF aquí estudiados (es decir, las condiciones socio-históricas, operativas y performáticas de los usos registrados). Sin embargo, consideramos que el contexto de interpretación de los significados de las plantas sí podría reproducirse sobre la base de fuentes bibliográficas o estudios ulteriores (del mismo modo que lo efectuado aquí a partir de las correspondencias botánicas ya descripto). Ejemplo de esto último sería la caracterización del sistema médico de los criollos del Chaco Húmedo -no realizado aún- con el fin de interpretar los usos medicinales de las plantas en su contexto particular.

En cuanto a los resultados encontrados, los altos valores registrados para la categoría "religiosidad popular" se hallarían sobredimensionados debido al sesgo que suponía el objetivo explícito de quienes condujeron la ENF, es decir, relevar las "creencias" y "supersticiones" de la población nacional (criolla) antes de que se mezclara con aquellas provenientes de los inmigrantes que arribaban al país. Dentro de esta categoría resultan destacables las diversas significaciones que muchas plantas adquieren como consecuencia de su condición de portadoras de "póra", es decir, entidades espirituales. En efecto, encontramos que dichas plantas solían evitarse por ser consideradas portadoras de "mal augurio", mientras que otras se utilizaban en rituales preventivos y propiciatorios. Al respecto, Fariña Núñez (1926) afirma que el vocablo "póra" -proveniente del idioma guaraní- hace referencia a una especie de "genius loci" que protege lugares y especies vegetales de la presencia de quienes llegan a 
perturbarlos. Esta sería otra manera de referirse a los típicos "dueños" de la vegetación propios de la religiosidad animista de los indígenas chaquenses (Tomasini, 1999; Wright, 2008; Siffredi, 2012; Tola \& Suárez, 2013), los cuales se consideran como entidades nohumanas dotadas de intencionalidad y poder que detentan la soberanía sobre cada especie vegetal, protegiendo a sus representantes y castigando a quienes las perjudican. Respecto a esta misma categoría de usos/significaciones, se infiere una homologación simbólica entre las características con las que se describen los rituales propiciatorios tendientes a obtener la "flor del curundú" (o "payé" o "reliquia") y aquellas empleadas para definir las entidades maléficas o nefastas de la "porá". En efecto, ambas significaciones resultan congruentes al hacer referencia a un poder numinoso encerrado en la planta que, en tanto tal, se describe de manera ambigua propiciando la fortuna en el juego o en el amor en algunos casos, o bien dejando traslucir su aspecto terrorífico manifestado en la forma de personajes monstruosos que atemorizan y pueden resultar mortales durante dichos rituales. Desde esta perspectiva, la "flor del curundú" podría considerarse como la materialización simbólica de tal poder numinoso.

Resulta paradójico que no se hayan registrado usos ni conocimientos relativos a la actividad ganadera, siendo esta una de las prácticas económicas más importantes entre los criollos de la región (antes de la llegada de la agricultura de los colonos europeos). En efecto, a este respecto sólo se mencionan usos de las plantas en medicina veterinaria recién en quinto lugar, con tan solo 23 datos etnobotánicos. Sin embargo, nada se menciona siquiera acerca del voluminoso corpus de conocimientos relativos a los forrajes nativos de la zona que sirven de alimento a cada una de las distintas especies de animales de cría. Pese a que no existen trabajos que registren tales datos en la zona, los resultados de estudios en áreas aledañas como los realizados en las costas del río Paraná en Entre Ríos (Fundación F. G. Bracht, 1984) y para el Chaco Semiárido (Scarpa, 2007), hacen suponer la existencia de un gran cúmulo de conocimientos al respecto. Entre las razones de esta omisión, podríamos suponer la condición indirecta que estos usos tendrían para los encuestadores (desde el momento que son pasivamente consumidos por los animales) y/o el hecho de haber sido considerados como datos de carácter "no-folklórico".

Otro de los aspectos distintivos en relación a estudios etnobotánicos realizados con criollos del Chaco hasta el momento, es que los datos aquí reproducidos incorporan un gran número de usos y significaciones sobre elementos vegetales propios del Dominio Amazónico. En efecto, estos últimos taxa evidencian una transgresividad mucho más marcada hacia el Chaco Húmedo -ver Adámoli (1973)- que hacia otras subregiones menos húmedas del Dominio Chaqueño. Entre estas especies pueden citarse los siguientes elementos conspicuos de la vegetación arbórea: Acrocomia aculeata (Jacq.) Lodd. ex Mart., Annona emarginata (Schltdl.) H. Rainer, Aspidosperma polyneurum Müll. Arg., Chloroleucon tenuiflorum (Benth.) Barneby \& J.W. Grimes, Chrysophyllum gonocarpum (Mart. \& Eichler) Engl., Eugenia uniflora L., E. pitanga (O. Berg) Nied., E. myrcianthes Nied., Ficus luschnathiana (Miq.) Miq., Ilex dumosa Reissek var. guaranina Loes., Jacaranda mimosifolia D. Don., Myrcianthes pungens (O. Berg) D. Legrand, Myrsine laetevirens (Mez) Arechav., Nectandra angustifolia (Schrad.) Nees \& Mart., Ocotea puberula (Rich.) Nees, O. acutifolia (Nees) Mez, Plinia trunciflora (O. Berg) Kausel, Sapium glandulosum (L.) Morong y Tabernaemontana catharinensis A. DC.

\section{Conclusiones}

Se registran 1242 datos etnobotánicos inéditos asignados a 308 taxa botánicos que fueron referidos bajo un total de 294 nombres vulgares para los cuales se pudo hallar una identificación taxonómica plausible a lo largo de 1137 citas bibliográficas. De estos datos, 814 (65,5\% del total) corresponden a usos medicinales de las plantas mientras que $428(33,7 \%)$ a los no-medicinales. Del análisis de estos últimos pudimos colegir que la mayoría de ellos $(120,78$ taxa) alude a significaciones de las plantas en la religiosidad de los criollos del Chaco Húmedo, 
seguido por las empleadas en construcciones (55, 47 taxa), en agricultura $(52,52$ taxa), alimentos (47, 38 taxa), mientras que las demás categorías de usos registran una participación mucho menor (menos de 23 usos cada una). Estos datos constituyen el mayor aporte a la etnobotánica de los criollos del Chaco Húmedo hasta el presente, tanto por su cantidad como por su calidad.

Se comprueba la necesidad de analizar el contexto socio-histórico-cultural de la fuente de origen de los datos a los fines de efectuar su interpretación cabal desde la perspectiva de la etnobotánica histórica, tanto respecto a la caracterización del acervo cultural al que estos responden (hispano-guaranítico) como al sesgo que evidencian hacia ámbitos asociados con su sistema de creencias, entre otras razones.

Se pone de manifiesto la posibilidad de aprovechar informaciones folklóricas de carácter histórico para recuperarlas en la forma de datos etnobotánicos, así como la conveniencia de efectuarlo. Esto último se evidencia en la imposibilidad de volver a registrar a campo muchos de ellos debido al largo tiempo transcurrido, así como la oportunidad de obtener datos originales para un complejo biocultural escasamente estudiado desde el punto de vista etnobotánico. Todo ello a partir de la aplicación de técnicas metodológicas de tipo cualitativo que maximizan la precisión y cantidad de datos recuperados, a pesar que estos se asignen a plantas referidas por su nombre vulgar. Se demuestra aquí que esto puede ser subsanado a partir de una búsqueda exhaustiva de datos bibliográficos acerca de las correspondencias botánicas de tales nombres, sobre los cuales se aplican criterios de selección o filtros sucesivos, en función de su pertenencia relativa a un área biogeográfica y a un grupo humano en particular; en nuestro caso, a los Criollos del Chaco Húmedo.

\section{Agradecimientos}

A Judith Farberman por habernos señalado la existencia de la ENF y la importancia de analizar los datos inéditos en ella incluidos. Al Instituto Nacional de Antropología y Pensamiento Latinoamericano (INAPL) por habernos permitido consultar los microfilms de la ENF y al personal de su biblioteca por su amabilidad. A Macarena Perusset y a los revisores por sus valiosas sugerencias para mejorar este trabajo. Al Consejo Nacional de Investigaciones Científicas y Tecnológicas (CONICET), institución de pertenencia de los autores.

\section{Bibliografía}

ADÁMOLI, J. 1973. Frecuencia, confinamiento y transgresividad en especies del Chaco Argentino. Bol. Soc. Argent. Bot. 15: 1-11.

AMORÍN, J. L. 1988. Guía taxonómica con plantas de interés farmacéutico. Colegio Oficial de Farmacéuticos y Bioquímicos de la Capital Federal, Buenos Aires. 80 pp.

ARENAS, P. 1987. La etnobotánica en el Gran Chaco. Memorias del IV Congreso Latinoamericano de Botánica, pp. 35-52. ICFES, Medellín.

AROVICH DE BOGADO, V. H. 2005. Encuesta de Folclore de 1921. Textos enviados desde el Territorio Nacional del Chaco. UNNE, Resistencia. 139 pp.

BURKART, R., N. BÁRBARO, R. O. SÁNCHEZ \& D. A. GÓMEZ. 1999. Eco-regiones de la Argentina. Administración de Parques Nacionales, Buenos Aires. $43 \mathrm{pp}$.

CAMPOS NAVARRO, R. \& G. F. SCARPA. 2013. The cultural-bound disease 'empacho' in Argentina. A comprehensive botanico-historical and ethnopharmacological review. J. Ethnopharmacol. 148: 349-360.

CAZES CAMARERO, P. L. 2000. Nombres vulgares de Asteraceae del Herbario del Museo "Juan A. Domínguez" (Facultad de Farmacia y Bioquímica UBA). Dominguezia 16: 15- 45.

COLOMBRES, A. 2012. Seres mitológicos argentinos. Colihue, Buenos Aires. 316 pp.

DAHHUR, A. 2016. Los maestros entre la condena y la aceptación de la medicina tradicional en la provincia de Buenos Aires. La cultura popular y la cultura docta en la Encuesta Nacional de Folclore de 1921. Sociedad y Discurso 28: 94-114.

DE LA PEÑA, M. R. \& J. F. PENSIERO. 2004. Catálogo de nombres comunes. LOLA, Buenos Aires. 373 pp.

DIMITRI, M. J. 1987. Enciclopedia argentina de agricultura y jardinería, Tomo 1: Descripción de las plantas cultivadas. ACME, Buenos Aires. 931 pp.

FARBERMAN, J. 2005. Las salamancas de Lorenza. Magia, hechicería y curanderismo en el Tucumán colonial. Siglo XXI editores Argentina, Buenos Aires. $286 \mathrm{pp}$.

FARIÑA NÚÑEZ, E. 1926. Conceptos estéticos. Mitos guaraníes. Imp. Mariana Pastor, Buenos Aires. 317 pp. 
FERNÁNDEZ LATOUR DE BOTAS, O. 2002. Cantares históricos argentinos. Del Sol, Buenos Aires. 352 pp.

FLORA ARGENTINA. 2017. Base de datos "Flora Argentina". The Andrew W. Mellon Foundation, IBODA, IMBIV, INTA. http://www.floraargentina. edu.ar/ [Consulta: Julio-Octubre de 2017].

FUNDACIÓN F. G. BRACHT (Ed.). 1984. Cultura tradicional del área del Paraná Medio. Instituto Nacional de Antropología, Buenos Aires. 323 pp.

GOBIERNO DE MÉXICO. 2017. Método de Evaluación Rápida de Invasividad (MERI) para especies exóticas en México Cirsium vulgare (Savi) (Ten., 1835). https:// www.gob.mx/cms/uploads/attachment/file/220996/ Cirsium_vulgare.pdf. [Consulta: 31/08/2017].

GUINZBURG, R. \& ADÁMOLI, J. 2006. Situación ambiental en el Chaco Húmedo. En BROWN, A., MARTÍNEZ ORTIZ, U., ACERBI, M. \& CORCUERA, J. (eds.), La Situación Ambiental Argentina 2005, pp. 103-112. Fundación Vida Silvestre Argentina, Buenos Aires.

HASSLER, E. 1909. Flórula Pilcomayensis. Trab. Mus. Farmacol. 21: 1-154.

KELLER, H. A., S. J. E. VELAZCO \& E. R. KRAUCZUK. 2016. Regeneración de plantas leñosas bajo arbustos aislados en un sector de los esteros del Iberá, Corrientes, Argentina. Implicancias etnoecológicas. Bonplandia 25: 103-114.

MAEDER, E. 2007. Panorama histórico. Del territorio indígena a la etapa provincial. En SÁNCHEZ, J. E., ALEMAN, J. A. \& A. PROSDOCIMI (eds.), Atlas Total de la República Argentina: Chaco. Tomo 6, pp. 22-29. Arte Gráfico Editorial Argentino, Buenos Aires.

MARTÍNEZ, G. J. 2010. Las plantas en la medicina tradicional de las Sierras de Córdoba. Un recorrido por la cultura campesina de Paravachasca y Calamuchita. Del Copista, Córdoba. 212 pp.

MARTÍNEZ CROVETTO, R. N. 1981a. Las plantas utilizadas en medicina popular en el Noroeste de Corrientes (Argentina). Miscelánea 69: 1-140.

MARTÍNEZ CROVETTO, R. N. 1981b. Plantas reguladoras de la fecundidad utilizadas en la medicina popular del Nordeste argentino. Parodiana 1: 97-117.

MARTÍNEZ CROVETTO, R. N. †. 2012. Estudios etnobotánicos V. Nombres de plantas y su utilidad según los mbya guaraní de Misiones, Argentina. Bonplandia 21: 109-133.

MEDEIROS, N. H. 2009. Etnobotánica histórica: princípios e procedimentos. Sociedade Brasileira de Etnobiologia e Etnoecologia, Recife. 83 pp.

MINISTERIO DE PLANIFICACIÓN FEDERAL, INVERSIÓN PÚBLICA Y SERVICIOS. 2006. Evaluación de impacto ambiental ruta provincial $\mathrm{N}^{\mathrm{o}}$ 6 Tramo: "San Bernardo - Las Breñas, Accesos a Las Breñas y San Bernardo. Capítulo n ${ }^{\circ}$ 4: Diagnóstico del área de influencia del proyecto. http://www.ucpypfe. gov.ar/PIVNG-1851/Cap4-Chaco02.pdf.
MONTESANO, A. 1913. Plantas Medicinales (Extranjeras e indígenas). Imprenta Suiza de Imsand y Cía., Buenos Aires. 396 pp.

MORELLO, J. \& C. SARAVIA TOLEDO. 1959. El bosque chaqueño II. La ganadería y el bosque en el Oriente de Salta. Rev. Agron. Noroeste Arg. 3: 209-258.

PARODI, D. 1886. Notas sobre algunas plantas usuales del Paraguay, de Corrientes y de Misiones. (2 $2^{\mathrm{a}}$. ed.). Imp. P. E. Coni e hijos, Buenos Aires. 123 pp.

PENNINGTON, M. S. 1904. Medicina popular en las Islas del Delta del Río Paraná. Trab. Mus. Farmacol. 8: 1-11.

PENSIERO, J. F., H. F. GUTIÉRREZ, A. M. LUCCHETTI, E. EXNER, V. KERN, E. BRNICH, L. OAKLEY, D. PRADO \& J. P. LEWIS. 2005. Flora Vascular de la Pcia. de Santa Fe. Claves para el reconocimiento de las familias y géneros. Catálogo sistemático de especies. UNL, Santa Fe. 403 pp.

PETETÍN, C. A. \& A. MARZOCCA. 1984. Patrón para nombres comunes de las malezas de la República Argentina. ASAM, Buenos Aires. 140 pp.

PIRONDO, A. 2016. Uso, manejo y acceso al recurso vegetal en comunidades rurales del macrosistema Iberá (Corrientes, Argentina). Tesis doctoral, UNNE, Corrientes. 196 pp.

QUIÑNONEZ, M. G. 2000. Inmigración en la provincia de Corrientes: políticas de poblamiento y realidad demográfica (1896-1914). En Actas del XX Encuentro de Geohistoria Regional, pp. 683-702. IIGHICONICET, Resistencia.

ROSSO, C. N. 2012. La etnobotánica de los grupos mocovíes de la reducción de San Javier, en el Gran Chaco, durante el siglo XVIII. Tesis Doctoral, UBA, Argentina. 306 pp.

ROSSO, C. N. \& G. F. SCARPA. 2012. Identificaciones botánicas de las plantas empleadas entre los mocovíes en la reducción San Javier durante el siglo XVIII a partir de la obra de Florián Paucke, S.J. En ARENAS, P. (ed.), Etnobotánica en zonas áridas y semiáridas del Cono Sur de Sudamérica, pp. 45-70. Sigma, Buenos Aires.

SCARPA, G. F. 2004. Medicinal plants used by the Criollos of Northwestern Argentine Chaco. J. Ethnopharmacol. 91: 115-135.

SCARPA, G. F. 2007. Etnobotánica de los criollos del oeste de Formosa: conocimientos tradicionales, valoración y manejo de plantas forrajeras. Kurtziana 33(1): 153-174.

SCARPA, G. F. 2012a. Las plantas en la vida de los criollos del oeste formoseño. Medicina, Ganadería, Alimentación y Viviendas Tradicionales. Rumbo Sur, Buenos Aires. 240 pp.

SCARPA, G. F. 2012b. "Palos, yuyos, pencas, bejucos y pastos": Los nombres de las plantas y su clasificación etnobotánica por los criollos del Chaco Semiárido Norte (NE Salta - W Formosa). En ARENAS, P. (ed.), Etnobotánica en zonas áridas y semiáridas del Cono Sur de Sudamérica, pp. 117-144. Sigma, Buenos Aires. 270 pp. 
SCARPA, G. F. 2017. Etnobotánica histórica de grupos criollos de Argentina II: Puesta en valor, adscripción cultural y análisis de los usos no medicinales presentados por el Gobierno argentino en la Exposición Universal de París de 1889. Bonplandia 26: 77-102.

SCARPA, G. F. \& L. ANCONATANI. 2017. Etnobotánica histórica de las Misiones Franciscanas del este de Formosa II: Identificación y análisis de datos inéditos y reelaboración integral de fuentes ya publicadas a partir de hallazgos documentales. Dominguezia 33: 37-79.

SCARPA, G. F., C. N. ROSSO \& L. ANCONATANI. 2016. Etnobotánica médica de grupos criollos de Argentina: Reconocimiento, análisis y puesta en valor de los datos presentados por el gobierno argentino en la Exposición Universal de París de 1889. Darwiniana, n.s. 4: 291-315.

SCHULZ, A. 1976. Nombres comunes de las plantas. Talleres Gráficos Moro Hnos., Resistencia. 234 pp.

SCHULZ, A. 1997†. Algunas plantas usuales del Nordeste argentino. Parodiana 10: 211-241.

SIFFREDI, A. 2012. Memorias Chorote. Gran Chaco Sudamericano. Editorial Académica Española, Saarbrücken. $176 \mathrm{pp}$.

THE NATURE CONSERVANCY (TNC), FUNDACIÓN VIDA SILVESTRE ARGENTINA (FVSA), FUNDACIÓN PARA EL DESARROLLO SUSTENTABLE DEL CHACO (DESDEL CHACO) Y WILDIFE CONSERVATION
SOCIETY BOLIVIA (WCS). 2005. Evaluación Ecorregional del Gran Chaco Americano / Gran Chaco Americano EcoregionalAssessment. Fundación Vida Silvestre Argentina, Buenos Aires. 24 pp.

TOLA, F. C. \& V. SUÁREZ. 2013. Diálogo sobre los existentes de un entorno superpoblado en el contexto de la marisca y la reivindicación política del territorio. En TOLA, F. C., C. MEDRANO \& L. CARDIN (eds.), Gran Chaco. Ontología, poder, afectividad, pp. 41-76. Asoc. Civil Rumbo Sur, Buenos Aires.

TOLEDO, V. M. \& N. BARRERA-BASSOLS. 2008. La memoria biocultural: La importancia ecológica de las sabidurías tradicionales. Icaria Editorial, Barcelona. 232 pp.

TOMASINI, A. 1999. Figuras protectoras de animales y plantas en la religiosidad de los indios Nivaclé (Chaco Boreal-Paraguay). Abya-Yala, Quito. 88 pp.

TROPICOS. 2017. Nomenclatural Data Base of Missouri Botanical Garden. St. Louis, USA. May. 2017. http://www.tropicos.org/ [Consulta: juliooctubre, 2017].

WERNICKE, E. 1944. Introducción por el traductor. En PAUCKE, F., Hacia allá y para acá. Una estadía entre los indios Mocobíes, 1749-1767. Volumen III, pp. XIII-XXII. Univ. Nac. de Tucumán, San Miguel de Tucumán.

WRIGHT, P. 2008. Ser-en-el-Sueño. Crónicas de historia y vida toba. Biblos, Buenos Aires. 285 pp.

Original recibido el 5 de febrero de 2018; aceptado el 4 de mayo de 2018. 
